Full Length Article

\title{
Elucidating the energy transfer process in mononuclear and binuclear lanthanide complexes of the anti-inflammatory drug ibuprofen: From synthesis to high luminescence emission
}

\author{
Tatiane C. de Oliveira ${ }^{a}$, Hudson P. Santos ${ }^{a}$, Marcelo G. Lahoud ${ }^{\mathrm{b}}$, Douglas F. Franco ${ }^{\mathrm{b}}$, \\ Ricardo O. Freire ${ }^{c}$, José Diogo L. Dutra ${ }^{c}$, Alexandre Cuin ${ }^{\mathrm{d}}$, Juliana F. de Lima ${ }^{\mathrm{a}}$, \\ Lippy F. Marques ${ }^{\text {a,* }}$ \\ a Grupo de Materiais Inorgânicos Multifuncionais (GMIM), Instituto de Química, Universidade do Estado do Rio de Janeiro, Rio de Janeiro 20550-013, Brazil \\ ${ }^{\mathrm{b}}$ Departamento de Química Geral e Inorgânica, Instituto de Química, Universidade Estadual Paulista Júlio de Mesquita Filho, UNESP, Araraquara, \\ SP 14801-970, Brazil \\ ${ }^{c}$ Pople Computational Chemistry Laboratory, Departamento de Química, Universidade Federal de Sergipe, São Cristóvão, SE 49100-000, Brazil \\ d Departamento de Química - ICE, Universidade Federal de Juiz de Fora, Juiz de Fora, MG 36036-330, Brazil
}

\section{A R T I C L E I N F O}

\section{Article history:}

Received 21 June 2016

Received in revised form

11 August 2016

Accepted 2 September 2016

Available online 15 September 2016

\section{Keywords:}

Photoluminescence

Ibuprofen

Nitrogen ligands

Lanthanides

\begin{abstract}
A B S T R A C T
This work presents the synthesis, solid state characterization and complete photoluminescence study of three new important classes of lanthanide complexes containing the non-steroidal anti-inflammatory drug (NSAID) Ibuprofen. The analytical and spectroscopic data reveals the formation of nine complexes with the general formula $\left[\mathrm{Ln}(\mathrm{Ibf})_{3}\left(\mathrm{H}_{2} \mathrm{O}\right)_{2}\right],\left[\mathrm{Ln}_{2}(\mathrm{Ibf})_{6}(\text { bpy })_{2}\right]$ and $\left[\mathrm{Ln}_{2}(\mathrm{Ibf})_{6}(\text { phen })_{2}\right]\left(\mathrm{Ln}=\mathrm{Eu}^{\mathrm{III}}, \mathrm{Gd}^{\mathrm{III}}\right.$ and Tb ${ }^{\mathrm{III}}$, $\mathrm{Ibf}=$ Ibuprofen ligand, $\mathrm{bpy}=2,2^{\prime}$ - bipyridine and phen $=1,10$-phenanthroline). The molecular structures of the Eu ${ }^{\text {III }}$ complexes were calculated using the RM1 model, and your optimized ground state geometries were used to calculated all details involved in the energy transfer process and compared with experimental data. The phosphorescence measurements of the $\mathrm{Gd}^{\mathrm{III}}$ complexes, allowed the identification of the lowest ligand triplet state, proving that the photoluminescence in the Eu ${ }^{\text {III }}$ and $\mathrm{Tb}^{\mathrm{III}}$ Ibuprofen complexes is proposed to be a ligand sensitized luminescence process. The presence of N,N-donors (bpy or phen) in the structure of the $\mathrm{Eu}^{\mathrm{III}}$ Ibuprofen complexes results in an 3 to 4 -fold increase in the quantum efficiency when compared with the $\mathrm{Eu}^{\mathrm{III}}$ complex without $\mathrm{N}, \mathrm{N}-$ donors ligands. The high emission quantum efficiency $(\eta=69-80 \%)$ for $\mathrm{Eu}^{\mathrm{III}}$ complexes showed that they can be potential candidates as emitters in biologic assays.
\end{abstract}

(c) 2016 Elsevier B.V. All rights reserved.

\section{Introduction}

In recent years, the lanthanides elements ( $\operatorname{Ln})$ have become to a wealth of advanced materials and technologies, including catalysts, magnets, optics and lasers, alloys, rechargeable batteries, electronics, imaging and bio analysis [1-8]. However, the usual impediment to the use of such lanthanide ions ( $\mathrm{Ln}^{\text {III }}$ ) systems is that the direct absorption of the $4 \mathrm{f}-4 \mathrm{f}$ excited states is very inefficient, with such transitions being parity forbidden and consequently resulting in very low absorption coefficients. In order to overcome this drawback, suitable chromophores have been employed as antennas or sensitizers that have the capability of transferring energy indirectly to the lanthanide ions [9]. This sensitization process consists of

\footnotetext{
* Corresponding author.

E-mail address: lippymarquesuerj@gmail.com (L.F. Marques).
}

the absorption of the light by the ligand in the ultraviolet (UV) region, followed by an intramolecular energy transference from the triplet state $\left(\mathrm{T}_{1}\right)$ of the ligand to an excited level of the $\mathrm{Ln}^{\mathrm{III}}$ ion. Ultimately, the excited $\operatorname{Ln}^{\mathrm{III}}$ ion decays to the ground state via photon emission in the visible or near infrared regions (Antenna Effect) [10]. In this context, the lanthanide complexes containing carboxylate ligands are the most largely investigated kinds of coordination compounds due the luminescent and higher thermal stabilities, which make them potential candidates for Light Conversion Molecular Devices (LCMDs) [11,12]. In particular, the Ibuprofen (Ibf), represented in Chart 1, is an optically active compound with both $S$ and $R$-isomers, belonging to non-steroidal antiinflammatory drug (NSAID) class. This drug is used to treat rheumatoid arthritis, headaches, fever and pains related with the inflammatory process. The Ibuprofen molecule contains a aromatic group able to absorption in the UV region, acting like a good 
<smiles>CC(C)Cc1ccc(C(C)C(=O)O)cc1</smiles>

Chart 1. Chemical structure of the Ibuprofen (Ibf).

antenna. Despite its structural simplicity, there are very few studies focused on solid state chemistry and optical properties of lanthanide complexes with Ibuprofen [13], being the majority of these studies associated to d block metal complexes [14-17]. Still, to the best of our knowledge, do not exist a detailed scrutiny of important energy transfer process in these luminescent compounds once that such are employed in molecular recognition of NSAID, as Ibuprofen $[18,19]$. In addition, previous studies show that the emission intensities and fluorescence lifetimes of lanthanide complexes are enhanced after introducing the second organic ligand as 2,2'bipyridine (bpy) or 1,10-phenanthroline (phen) [20,21]. These ligands act as energy donors and enhance the fluorescence intensities of lanthanide complexes in a so-called "synergistic effect". The introduction of these ligands not only reinforces the fluorescence emission, but also increases the thermal stability and fulfills the coordination numbers of the lanthanide complexes. In the field of the lanthanide coordination compounds, theoretical tools can be helpful in the investigation of these systems [22-24]. The development of the accurate semiempirical RM1 model [25] for trivalent lanthanide ions has allowed the prediction of the ground states geometries of large lanthanide coordination compounds. Based on the knowledge of this geometry and using different approaches, several spectroscopic properties can be predicted and shed light on numerous details of the energy transfer mechanism in these compounds. We describe herein the synthesis, structural characterization and full photoluminescence properties of three mononuclear $\left[\operatorname{Ln}(\mathrm{Ibf})_{3}\left(\mathrm{H}_{2} \mathrm{O}\right)_{2}\right](\mathrm{Ln}=\mathrm{Eu} \mathrm{1}$; Gd 2; Tb 3; where $\mathrm{Ibf}=$ ibuprofenate anion) and six binuclear complexes: $\left[\operatorname{Ln}_{2}(\mathrm{Ibf})_{6}(b p y)_{2}\right](\mathrm{Ln}=\mathrm{Eu} 4$; Gd 5 and $\mathrm{Tb} 6$, where bpy $=2,2^{\prime}$ bipyridine) and $\left[\operatorname{Ln}_{2}(\mathrm{Ibf})_{6}(\text { phen })_{2}\right]$ ( $\operatorname{Ln}=\mathrm{Eu} \mathrm{7;} \mathrm{Gd} 8$ and Tb 9, where phen=1,10-phenanthroline). Spectroscopic properties as $\Omega_{\lambda}$ intensity parameters $(\lambda=2,4$ and 6$)$, energy transfer $\left(W_{\mathrm{ET}}\right)$ and back-transfer $\left(\mathrm{W}_{\mathrm{BT}}\right)$ rates, radiative $\left(\mathrm{A}_{\mathrm{rad}}\right)$ and nonradiative $\left(A_{\text {nrad }}\right)$ decay rates, quantum efficiency $(\eta)$ and quantum yield $(q)$ of Eu ${ }^{\text {III }}$ compounds were theoretically modeled using the electronic and spectroscopic semiempirical models and compared with those experimental values.

\section{Experimental}

\subsection{Materials and measurements}

All synthetic procedures were performed in air and $\mathrm{TbCl}_{3} \cdot 6 \mathrm{H}_{2} \mathrm{O}$, (R,S)-Ibuprofen (Ibf), 2,2'-bipyridine (bpy) and 1,10phenanthroline (phen) were obtained either from Aldrich ${ }^{\circledR}$ or Fluka ${ }^{\circledR}$ and used as received. $\mathrm{EuCl}_{3} \cdot 6 \mathrm{H}_{2} \mathrm{O}$ and $\mathrm{GdCl}_{3} \cdot 6 \mathrm{H}_{2} \mathrm{O}$ were prepared by dissolving europium and gadolinium oxide in hydrochloric acid solution and then dried. Elemental analyses for C, $\mathrm{H}$ and $\mathrm{N}$ were carried out using a Perkin Elmer 2400CHN analyzer. The metal contents were determined by complexometric titrations with standard EDTA solution and using xilenol orange as indicator [26]. FTIR spectra were recorded with a Perkin Elmer Spectrum One model using the ATR mode in the wavenumber range of $4000-400 \mathrm{~cm}^{-1}$ with an average of 128 scans and $4 \mathrm{~cm}^{-1}$ of spectral resolution. Powder diffraction analysis (PXRD) was performed using a Bruker AXS D8 da Vinci diffractometer (the generator was set at $40 \mathrm{kV}$ and $40 \mathrm{~mA}$ ), equipped with Ni-filtered
CuK $\alpha$ radiation $(\lambda=1.5418 \AA$ ), a Lynxeye linear position-sensitive detector and the following optics: primary beam Soller slits $\left(2.94^{\circ}\right)$, fixed divergence slit $\left(0.3^{\circ}\right)$ and receiving slit $(9.0 \mathrm{~mm})$, where the polycrystalline compounds were previously grounded in an agate mortar and they were deposited in hollow of thin glass sample-holder plate, with nearly zero-background. The diffraction data of all compounds were collected by overnight scans in the $2 \theta$ range of $6-105^{\circ}$ with steps of $0.02^{\circ}$ degree. Diffuse reflectance (DR) spectra were acquired with a Cary 500 spectrophotometer from 200 to $500 \mathrm{~nm}$ with spectral resolution of $1 \mathrm{~nm}$. Thermal analysis (TG curves) were obtained on a Shimadzu TG - 60 equipment where about 6 to $10 \mathrm{mg}$ of samples were heated at $10^{\circ} \mathrm{C} / \mathrm{min}$ from room temperature to $800^{\circ} \mathrm{C}$ in a dynamic nitrogen atmosphere (flow rate $=100 \mathrm{~mL} / \mathrm{min}$ ). The luminescence excitation and emission spectra were recorded using a Jobin - Yvon Model Fluorolog FL3 - 22 spectrophotometer equipped with a R928 Hamamatsu photomultiplier and $450 \mathrm{~W}$ xenon lamp as excitation source and the spectra were corrected with respect to the Xe lamp intensity and spectrometer response. Measurements of emission decay were performed with the same equipment by using a pulsed $\mathrm{Xe}(3 \mu \mathrm{s}$ bandwidth) source. Experimental intensity parameters, $\Omega_{\lambda}$, for the $\left[\mathrm{Eu}(\mathrm{Ibf})_{3}\left(\mathrm{H}_{2} \mathrm{O}\right)_{2}\right] \mathbf{1}$, $\left[\mathrm{Eu}_{2}(\mathrm{Ibf})_{6}(\mathrm{bpy})_{2}\right] \mathbf{4}$ and $\left[\mathrm{Eu}_{2}(\mathrm{Ibf})_{6}(\mathrm{phen})_{2}\right] \mathbf{7}$ were determined from the emission spectra using the following equation $[27,28]$ :

$\Omega_{\lambda}=\frac{3 \hbar c^{3} A_{0 \rightarrow J}}{4 e^{2} \omega^{3} \chi\left\langle{ }^{7} F_{J}\left\|U^{(\lambda)}\right\|^{5} D_{0}\right\rangle^{2}}$

where $\chi$ is the Lorentz local field correction term, given by $\chi=n$ $(n+2)^{2} / 9 \chi=\frac{\mathrm{n}(\mathrm{n}+2)^{2}}{9}$ and is $\left\langle{ }^{7} F_{J}\left\|U^{(\lambda)}\right\|^{5} D_{0}\right\rangle^{2}$ a squared reduced matrix element with value of 0.0032 for the ${ }^{5} \mathrm{D}_{0} \rightarrow{ }^{7} \mathrm{~F}_{2}$ transition and 0.0023 for the ${ }^{5} \mathrm{D}_{0} \rightarrow{ }^{7} \mathrm{~F}_{4}$ one. The refractive index $(n)$ has been assumed equal to 1.5 . In this work, the ${ }^{5} \mathrm{D}_{0} \rightarrow{ }^{7} \mathrm{~F}_{6}$ transition was not observed experimentally; consequently, the experimental $\Omega_{6}$ parameter could not be estimated. The spontaneous emission coefficient, $A_{01}=0.31 \times 10^{-11}(n)^{3}\left(\nu_{01}\right)^{3}$, leading to an estimated value around $50 \mathrm{~s}^{-1}$ for the refractive index $(n)$ defined above. In Eq. (1), the $A_{0 \lambda}$ term, where $\lambda=2$ and 4, represents the spontaneous emission coefficients of the ${ }^{5} \mathrm{D}_{0} \rightarrow{ }^{7} \mathrm{~F}_{2}$ and ${ }^{5} \mathrm{D}_{0} \rightarrow{ }^{7} \mathrm{~F}_{4}$ transitions, which can be calculated from ${ }^{5} \mathrm{D}_{0} \rightarrow{ }^{7} \mathrm{~F}_{1}$ reference transition (magnetic dipole mechanism), therefore this transition is practically insensitive to chemical environment changing, Eq. (2).

$A_{0 \lambda}=\frac{v_{01}}{v_{0 \lambda}} \frac{S_{0 \lambda}}{S_{01}}\left(A_{01}\right)$

where $S_{01}$ and $S_{0 \lambda}$ are the areas under the curves of the ${ }^{5} \mathrm{D}_{0} \rightarrow{ }^{7} \mathrm{~F}_{1}$ and ${ }^{5} \mathrm{D}_{0} \rightarrow{ }^{7} \mathrm{~F}_{\lambda}$ transitions, with $\nu_{01}$ and $\nu_{0 \lambda}$ being their energy barycenters respectively.

\subsection{Synthesis of the $\left[\mathrm{Ln}(\mathrm{Ibf})_{3}\left(\mathrm{H}_{2} \mathrm{O}\right)_{2}\right]$ complexes}

A solution of sodium ibuprofenate (NaIbf) was prepared by the addition of $\mathrm{NaOH}$ aqueous solution $\left(0.40 \mathrm{~mL}, 1 \mathrm{~mol} \mathrm{~L}^{-1}\right)$ to an aqueous suspension $(30 \mathrm{~mL})$ containing $84 \mathrm{mg}(0.40 \mathrm{mmol})$ of Ibuprofen. To this solution was added the respective lanthanide chloride aqueous solutions $(10 \mathrm{~mL}, 0.13 \mathrm{mmol})$ until total precipitation of the complexes. The precipitates were washed three times with hot distilled water, filtered and dried in a desiccator over anhydrous calcium chloride.

[Eu(Ibf) $\left.)_{3}\left(\mathrm{H}_{2} \mathrm{O}\right)_{2}\right]$ 1: Yield: 73\%. Anal. Calc. for $\mathrm{C}_{39} \mathrm{H}_{55} \mathrm{O}_{8} \mathrm{Eu}$ : C: 58.2, H: 6.9 \% Eu: 18.9 \%; Found: C: 58.5 , H: 6.7, Eu: $18.9 \%$.

[Gd $\left.(\mathrm{Ibf})_{3}\left(\mathrm{H}_{2} \mathrm{O}\right)_{2}\right]$ 2: Yield: $74 \%$. Anal. Calc. for $\mathrm{C}_{39} \mathrm{H}_{55} \mathrm{O}_{8} \mathrm{Gd}$ : C: 57.8 , H: 6.8, Gd: 19.4 \%; Found: C: 58.1, H: 6.5, Tb: 19.3 \%. 
[Tb(Ibf) $\left.)_{3}\left(\mathrm{H}_{2} \mathrm{O}\right)_{2}\right]$ 3: Yield of $77 \%$. Anal. Calc. for $\mathrm{C}_{39} \mathrm{H}_{55} \mathrm{O}_{8} \mathrm{~Tb}$ : C: 57.7, H: 6.8, Tb: 19.6 \%; Found: C: 57.8, H: 6.7, Tb: $19.4 \%$.

\subsection{Synthesis of the $\left[\operatorname{Ln}_{2}(\mathrm{Ibf})_{6}(\mathrm{bpy})_{2}\right]$ complexes}

An ethanolic solution $(10 \mathrm{~mL})$ containing $21 \mathrm{mg}(0.13 \mathrm{mmol})$ of $2,2^{\prime}$-bipyridine was slowly added to an aqueous suspension $(30 \mathrm{~mL})$ containing $84 \mathrm{mg}$ of Ibuprofen $(0.40 \mathrm{mmol}), 50 \mathrm{mg}$ of $\mathrm{LnCl}_{3} \cdot 6 \mathrm{H}_{2} \mathrm{O}(0.13 \mathrm{mmol})$ and $\mathrm{NaOH}$ aqueous solution $(0.40 \mathrm{~mL}$, $1 \mathrm{~mol} \mathrm{~L}^{-1}$ ). The mixture was stirred at room temperature for $24 \mathrm{~h}$ and a white solid was formed. The solid was filtered, washed three times with ethanol and acetone and dried in a desiccator over anhydrous calcium chloride.

$\left[\mathrm{Eu}_{2}(\mathrm{Ibf})_{6}(\text { bpy })_{2}\right]$ 4: Yield: $91 \%$. Anal. Calc. for $\mathrm{C}_{98} \mathrm{H}_{118} \mathrm{O}_{12} \mathrm{~N}_{4} \mathrm{Eu}_{2}$ : C: 63.7 , H: 6.44, N: 3.03, Eu: $16.4 \%$; Found: C: $63.8, \mathrm{H}: 6.46, \mathrm{~N}$ : 3.04, Eu: $16.3 \%$.

$\left[\mathrm{Gd}_{2}(\mathrm{Ibf})_{6}(\text { bpy })_{2}\right]$ 5: Yield: $88 \%$. Anal. Calc. for $\mathrm{C}_{98} \mathrm{H}_{118} \mathrm{O}_{12} \mathrm{~N}_{4} \mathrm{Gd}_{2}$ : C: 63.2, H: 6.29, N: 3.04, Gd: 16.9 \%; Found: C: 63.4, H: 6.27, N: 3.04, Gd: $16.7 \%$.

$\left[\mathrm{Tb}_{2}(\mathrm{Ibf})_{6}(\text { bpy })_{2}\right] \mathbf{6}$ : Yield of $79 \%$. Anal. Calc. for $\mathrm{C}_{98} \mathrm{H}_{118} \mathrm{O}_{12} \mathrm{~N}_{4} \mathrm{~Tb}_{2}$ : C: 63.0, H: 6.28, N: 3.03, Tb: $17.0 \%$; Found: C: 63.2, H: 6.27, N: 3.04, Tb: $17.0 \%$.

\subsection{Synthesis of the $\left[\operatorname{Ln}_{2}(\mathrm{Ibf})_{6}(\text { phen })_{2}\right]$ complexes}

Compounds 7-9 were obtained by applying the same synthetic procedure as described for 4-6, except that 1,10-phenanthroline (24 mg, $0.13 \mathrm{mmol}$ ) was used instead of 2,2'-bipyridine.

$\left[\mathrm{Eu}_{2}(\mathrm{Ibf})_{6}(\text { phen })_{2}\right]$ 7: Yield: $85 \%$. Anal. Calc. for $\mathrm{C}_{102} \mathrm{H}_{118} \mathrm{O}_{12} \mathrm{~N}_{4} \mathrm{Eu}_{2}$ : C: $64.6, \mathrm{H}: 6.27, \mathrm{~N}: 2.96$, Eu: $16.0 \%$; Found: C: $64.5, \mathrm{H}: 6.25$, N: 2.98, Eu: $15.8 \%$.

$\left[\mathrm{Gd}_{2}(\mathrm{Ibf})_{6}(\text { phen })_{2}\right]$ 8: Yield: $88 \%$. Anal. Calc. for $\mathrm{C}_{102} \mathrm{H}_{118} \mathrm{O}_{12} \mathrm{~N}_{4} \mathrm{Gd}_{2}$ : C: 64.2, H: 6.24, N: 2.94, Gd: 16.5 \% ; Found: C: 64.9, H: 6.19, N: 2.95, Gd: $16.1 \%$.

$\left[\mathrm{Tb}_{2}(\mathrm{Ibf})_{6}(\text { phen })_{2}\right]$ 9: Yield of $86 \%$. Anal. Calc. for $\mathrm{C}_{102} \mathrm{H}_{118} \mathrm{O}_{12} \mathrm{~N}_{4} \mathrm{~Tb}_{2}$ : C: $64.1, \mathrm{H}: 6.23, \mathrm{~N}: 2.93, \mathrm{~Tb}: 16.6 \%$; Found: C: 64.2, H: 6.20, N: 2.92, Tb: $16.5 \%$.

All the compounds are stable in air, non hygroscopic and partially soluble in ethanol, methanol and acetone. When exposed to UV light, the compounds exhibited luminescence in the primary colors: red (for the 1, 4, and $\mathbf{7}$ compounds) and green (for the 3, $\mathbf{6}$ and $\mathbf{9}$ compounds).

\subsection{Theoretical studies}

\subsubsection{Ground state geometries calculation}

The accurate prediction of the ground state geometry is fundamental in a theoretical investigation of the spectroscopic properties of a luminescent lanthanide system. There are two possibilities based on quantum theory: effective core potentials (ECPs) [29] associated with ab initio or DFT methods and Semiempirical approach. At first, $a b$ initio or DFT methods are always more accurate, however in two works we demonstrate that the results obtained with our semiempirical Sparkle Model are comparable to the results obtained with the ab initio or DFT calculations with ECPs on complexes of a size large enough to be of value to practical use [30,31]. Currently, we have five different Sparkle Models: Sparkle/AM1 [32], Sparkle/PM3 [33], Sparkle/PM6 [34], Sparkle/PM7 [35], and Sparkle/RM1 [36]. More recently we parameterized the RM1 model for trivalent lanthanide ions [37]. In this new parameterization the model attaches a set of semiempirical $5 d, 6 s$, and $6 p$ orbitals to describe the valence shell, which always contains 3 electrons for all lanthanide trications. Our results suggest that this new model is more general and more accurate than all Sparkle Models [37]. In the present work we evaluated the accuracy of all semiempirical models (five Sparkle Models and new RM1 model). As measure of accuracy we use the adjustment of the Judd-Ofelt intensity parameters. In the next section we demonstrate the high dependence of the intensity parameters with the geometry of the coordination polyhedra of the system. Based on the results we decided to perform the optimization of the geometries using our new RM1 model for trivalent lanthanide ions. The keywords used were RM1; PRECISE; GNORM $=0.25$; $\mathrm{T}=10 \mathrm{D} ; \mathrm{GEO}-\mathrm{OK}$ and $\mathrm{XYZ}$.

\subsubsection{Excited states calculations}

RM1 geometries were used to calculate the excited state energies (singlet and triplet) by using the semiempirical INDO/S - CIS method [38,39]. (Intermediate Neglect of Differential Overlap/Spectroscopic - Configuration Interaction Single) implemented in ORCA [40].

\subsubsection{Judd-Ofelt intensity parameters and radiative decay rate}

According to the Judd-Ofelt theory, the central lanthanide ion is affected by the nearest neighbor atoms, through a static electric field also referred as crystal or ligand field. The intensity parameters were theoretically calculated for by the following equation:

$\Omega_{\lambda}=(2 \lambda+1) \sum_{t}^{\lambda-1, \lambda+1(\text { odd })} \sum_{p=-t}^{t(\text { all })} \frac{\left|B_{\lambda t p}\right|^{2}}{(2 t+1)}$

where the parameter $B_{\lambda t p}$ is expressed by:

$B_{\lambda t p}=B_{\lambda t p}^{e . d .}+B_{\lambda t p}^{\text {d.c. }}$

In Eq. (4), the first term corresponds to the forced electric dipole contribution $\left(B_{\lambda t p}^{\text {e.d. }}\right)$ is given by:

$B_{\lambda t p}^{e . d .}=\frac{2}{\Delta E}\left\langle r^{t+1}\right\rangle \theta(t, \lambda) \gamma_{p}^{t}$

and the second term corresponds to the dynamic coupling contribution $\left(B_{\lambda t p}^{d . c .}\right)$ and is determined by the equation:

$B_{\lambda t p}^{\text {d.c. }}=-\left[\frac{(\lambda+1)(2 \lambda+3)}{2 \lambda+1}\right]^{1 / 2}\left\langle r^{\lambda}\right\rangle\left(1-\sigma_{\lambda}\right)\left\langle f\left\|C^{(\lambda)}\right\| f\right\rangle \Gamma_{p}^{t} \delta_{t, \lambda+1}$

where $\Delta E$ is a constant introduced by Malta being approximately given by the energy difference between the ground state barycenters and the first excited state configuration of opposite parity. The $\left\langle r^{\lambda}\right\rangle$ are the radial integrals whose values for $\mathrm{Eu}^{\mathrm{III}}$ ion [41]. The term $\left(1-\sigma_{\lambda}\right)$ is a shielding constant due to filled sublevels $5 s$ and $5 p$ of the lanthanide ion [42]. $C^{(\lambda)}$ is a tensor operator of rank $\lambda$ $(\lambda=2,4$, and 6$) . \delta_{t, \lambda+1}$ is the Kronecker delta function. In Eqs. (5) and (6) the quantities $\gamma_{p}^{t}$ and $\Gamma_{p}^{t}$ are calculated by:

$\gamma_{p}^{t}=\left(\frac{4 \pi}{2 t+1}\right)^{1 / 2} e^{2} \sum_{j} \rho_{j}\left(2 \beta_{j}\right)^{t+1} \frac{g_{j}}{R_{j}^{t+1}} Y_{p}^{t^{*}}\left(\theta_{j}, \phi_{j}\right)$

$\Gamma_{p}^{t}=\left(\frac{4 \pi}{2 t+1}\right)^{1 / 2} \sum_{j} \frac{\alpha_{j}}{R_{j}^{t+1}} Y_{p}^{t^{*}}\left(\theta_{j}, \phi_{j}\right)$

The variables $\theta_{j}$ and $\varphi_{j}$, Eqs. (7) and (8), correspond to angles in spherical coordinates from $j$ ligand to metal center. Thus, the dependency between the theoretical intensity parameters and compounds geometry can be noted.

The limitations in the intensity parameters calculation consist in determining the quantities, $\gamma_{p}^{t}$ and $\Gamma_{p}^{t}$. As a result, it is necessary to use the experimental intensity parameters. The charge factors and polarizabilities, used in $\gamma_{p}^{t}$ and $\Gamma_{p}^{t}$ calculations, respectively, are adjusted in order to reproduce the experimental intensity parameters. The usual procedure is to define a set of charge factors 
$\left(g_{s}\right)$ and polarizabilities $\left(\alpha_{s}\right)$ associated with Eu-L bonds (where $\mathrm{L}=$ ligand atom) and adjusts them to reproduce the experimental intensity parameters values by minimizing the following error function:

$F_{\text {resp }}=\left(\Omega_{2}^{\text {calc }}-\Omega_{2}^{\exp }\right)^{2}+\left(\Omega_{4}^{\text {calc }}-\Omega_{4}^{\text {exp }}\right)^{2}$

Recently, when our group procedure with a systematic spectroscopic study of a large number of similar compound, we observed that the adjustment of the $\Omega_{2}$ and $\Omega_{4}$ parameters could be perfectly performed for different sets of charge factors and polarizabilities. This fact leads to a problem of reproducibility of the methodology. To solve this problem, we proposed in a recent paper a new methodology [43]. Using only three adjustable parameters $(Q, D$, and $C)$ it was shown that it is possible to adjust a unique set of charge factors and polarizabilities considered for the same geometry and the same set of experimental $\Omega_{2}$ and $\Omega_{4}$ parameters. Through a series of tests using crystallographic structures it has been shown that the ratio between $D$ and $C$ adjustable parameters has a value greater than 1 where the intensity experimental parameters were well adjusted. Given this observation, it was then proposed that the ratio $D / C$ could be used as a setting acceptance criteria carried out with the Uniqueness QDC model [43]. Based on this premise that we chose the RM1 model as the most appropriate to be used in this work.

\subsubsection{Radiative decay rate}

An important role to predict the theoretical radiative decay rate $\left(A_{\text {rad }}\right)$ is given by the calculated intensity parameters. The $A_{\text {rad }}$ is calculated by the following equation:

$A_{\text {rad }}\left({ }^{5} D_{0}-{ }^{7} F_{J}\right)=\frac{64 \pi^{4} \nu^{3}}{3 h(2 J+1)}\left[\frac{n\left(n^{2}+2\right)^{2}}{9} S_{e d}+n^{3} S_{m d}\right]$

where $\nu$ is the difference of energy between the ${ }^{5} \mathrm{D}_{0}$ and ${ }^{7} \mathrm{~F}_{\mathrm{J}}$ states (in $\mathrm{cm}^{-1}$ ), $\mathrm{h}$ is the Planck constant, $2 J+1$ is the degeneracy of the initial state, and $n$ is the refractive index of the medium, usually assumed to be equal to $1.5 . S_{e d}$ and $S_{m d}$ are the magnetic dipole and forced electric dipole mechanisms, respectively.

\subsubsection{Intramolecular energy transfer in the ibuprofen complexes}

The nonradiative energy transfer rates involving the excited states of the ligands and of the Eu ${ }^{\mathrm{III}}$ ion were theoretically studied by using the Malta's models [44] and can be inferred from the sum of two terms, $W_{E T}^{m p}$ and $W_{E T}^{e x}$. The first one corresponds to the energy transfer rate obtained from the multipolar mechanism. The last one corresponds to the energy transfer rate obtained from the exchange mechanism $W_{E T}^{m p}$ and $W_{E T}^{e x}$ are expressed in Eqs. (11) and (12), respectively.

$$
\begin{aligned}
W_{E T}^{m p}= & \frac{2 \pi}{\hbar} \frac{e^{2} S_{L}}{(2 J+1) G} F \\
& \times \sum_{\lambda}\left(\frac{2\left(1-\sigma_{1}\right)^{2} \Omega_{\lambda}^{e . d .}}{R_{L}^{6}}+\gamma_{\lambda}\right)\left\langle\psi^{*} J^{*}\left\|U^{(\lambda)}\right\| \psi J\right\rangle \\
W_{E T}^{e x}= & \frac{8 \pi}{3 \hbar} \frac{e^{2}\langle 4 f \mid L\rangle^{4}}{(2 J+1) R_{L}^{4}} F\left\langle\psi^{*} J^{*}\|S\| \psi J\right\rangle^{2} \\
& \times \sum_{m}\left|\left\langle\varphi\left|\sum_{k} \mu_{z}(k) S_{m}(k)\right| \varphi^{*}\right\rangle\right|^{2}
\end{aligned}
$$

From Eq. (10), it can observe that multipolar mechanism depends on $\Omega_{\lambda}^{\text {e.d. }}$, the so-called intensity parameters (e.d.=electric dipole contribution) which appear in the well-known theory of $4 \mathrm{f}-4 \mathrm{f}$ intensities. The parameters $\Omega_{\lambda}^{\text {e.d. }}$ are obtained from intensity parameters calculations, so the $\Omega_{\lambda}$ theoretical prediction also plays an important role to calculate the energy transfer and back-
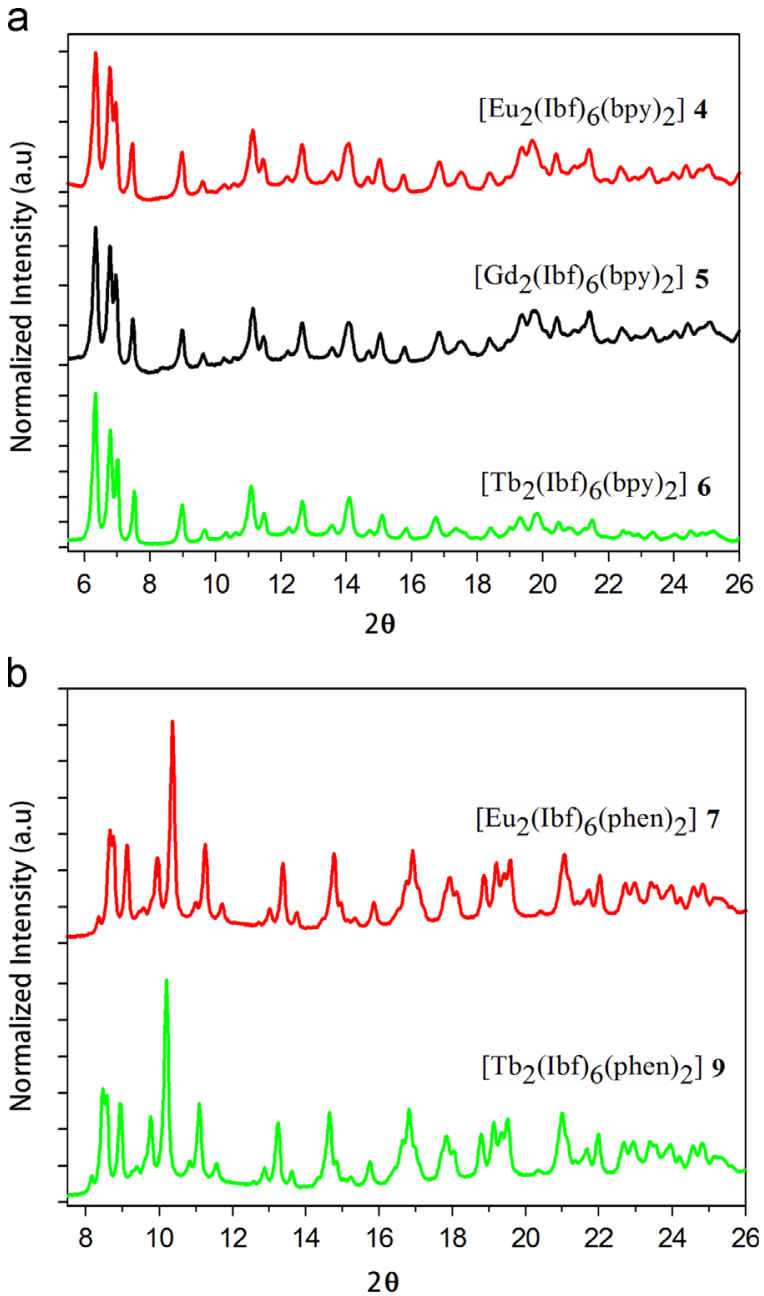

Fig. 1. X-ray powder diffraction patterns (PXRD) of the complexes (a) $\left[\operatorname{Ln}_{2}(\mathrm{Ibf})_{6}(\mathrm{bpy})_{2}\right](\mathbf{4}, \mathbf{5}$ and $\mathbf{6})$ and (b) $\left[\operatorname{Ln}_{2}(\mathrm{Ibf})_{6}(\text { phen })_{2}\right](\mathbf{7}$ and 9).

transfer rates by the multipolar mechanism. The term $\gamma_{\lambda}$ are calculated by:

$\gamma_{\lambda}=(\lambda+1) \frac{\left\langle r^{\lambda}\right\rangle^{2}}{\left(R_{L}^{\lambda+2}\right)^{2}}\left\langle 3\left\|C^{(\lambda)}\right\| 3\right\rangle^{2}\left(1-\sigma_{\lambda}\right)^{2}$

The term $F$ corresponds to the factor dependent of the temperature, and it contains a sum about the Frank Condon's Factors, given by:

$F=\frac{1}{\hbar \gamma_{L}} \sqrt{\frac{\ln 2}{\pi}} \exp \left[-\left(\frac{\Delta}{\hbar \gamma_{L}}\right)^{2} \ln 2\right]$

The quantity $\Delta$ is the energy gap between the donor (ligand singlet and triplet levels) and acceptor (lanthanide excited states) involved in the transfer process. The factor $\hbar \gamma_{\mathrm{L}}$ is the ligand state bandwidth-at-half-maximum (in $\mathrm{cm}^{-1}$ ).

\subsubsection{Rates equations and quantum yield calculations}

The emission quantum yield $(q)$ given by Eq. (15) is defined as the ratio between the intensities of light absorbed and emitted.

$q=\frac{A_{\text {rad }} \eta_{{ }^{5} D_{0}}}{\varphi \eta_{S_{0}}}$

where $\eta^{5} D_{0}$ is the population of the ${ }^{5} \mathrm{D}_{0}$ emitting level and $\eta_{S_{0}}$ and $\varphi$ correspond to the population and the rate of absorption of the $S_{0}$ singlet level, respectively. 
a

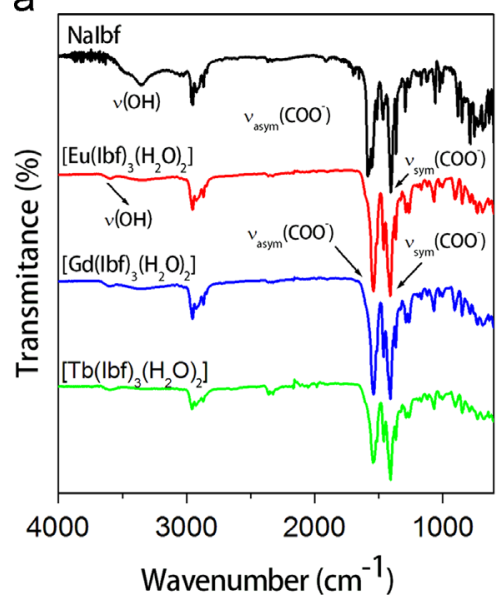

b

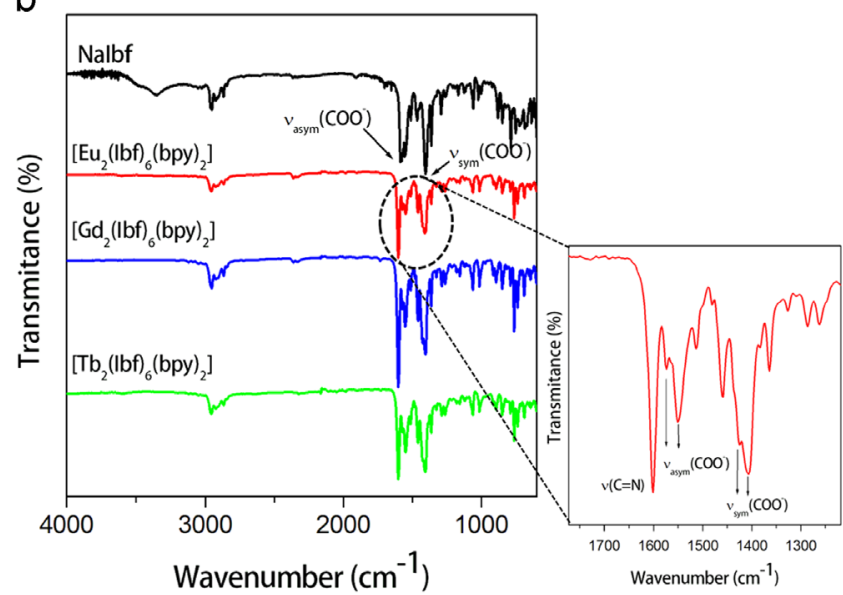

C

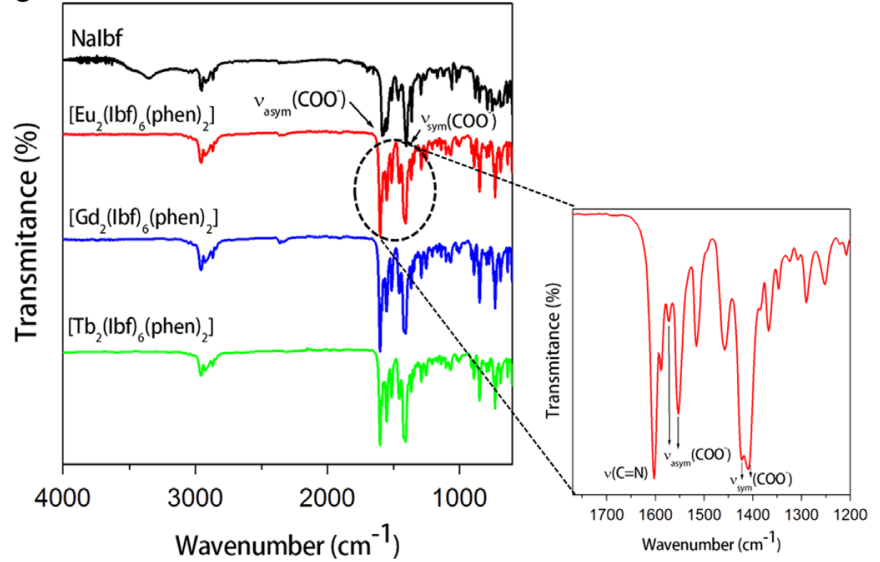

Fig. 2. FTIR spectra of the NaIbf sodium salt and Ibuprofen series: (a) [ $\mathrm{Ln}$ $\left.(\mathrm{Ibf})_{3}\left(\mathrm{H}_{2} \mathrm{O}\right)_{2}\right](\mathbf{1 - 3})$, (b) $\left[\mathrm{Ln}_{2}(\mathrm{Ibf})_{6}(\mathrm{bpy})_{2}\right]$ (4-6) and (c) $\left[\mathrm{Ln}_{2}(\mathrm{Ibf})_{6}(\text { phen })_{2}\right]$ (7-9) $(\mathrm{Ln}=\mathrm{Eu}, \mathrm{Gd}$ and $\mathrm{Tb})$.

The normalized level populations, $\eta_{j}$, are obtained from appropriate equations rate such as:

$\frac{d \eta_{j}}{d t}=-\left(\sum_{i \neq j} W_{j i}\right) \eta_{j}+\sum_{i \neq j} W_{i j} \eta_{i}$

$W_{j i}$ or $W_{i j}$ represent the transition and transfer rate between the $i$ and $j$ states, or $j$ and $i$ states. The detailed procedure for obtaining the numerical solution of the equations rates and emission quantum yield is described in literature [44,45].
Table 1

Wavenumbers values (in $\left.\mathrm{cm}^{-1}\right)$ of $\nu_{\text {asym }}\left(\mathrm{COO}^{-}\right), \nu_{\mathrm{sym}}\left(\mathrm{COO}^{-}\right)$and $\Delta \nu$ of the Ibuprofen sodium salt (NaIbf) and complexes.

\begin{tabular}{llll}
\hline Compounds & $\nu_{\text {asym }}\left(\mathbf{C O O}^{-}\right) / \mathbf{c m}^{-\mathbf{1}}$ & $\nu_{\text {sym }}\left(\mathbf{C O O}^{-}\right) / \mathbf{c m}^{-\mathbf{1}}$ & $\Delta \nu / \mathbf{c m}^{-\mathbf{1}}$ \\
\hline $\mathrm{NaIbf}$ & $1587(\mathrm{~s})$ & $1405(\mathrm{~s})$ & 182 \\
{$\left[\mathrm{Eu}(\mathrm{Ibf})_{3}\left(\mathrm{H}_{2} \mathrm{O}\right)_{2}\right] \mathbf{1}$} & $1545(\mathrm{vs})$ & $1411(\mathrm{vs})$ & 134 \\
{$\left[\mathrm{~Tb}(\mathrm{Ibf})_{3}\left(\mathrm{H}_{2} \mathrm{O}\right)_{2}\right] \mathbf{2}$} & $1545(\mathrm{vs})$ & $1411(\mathrm{vs})$ & 134 \\
{$\left[\mathrm{Gd}(\mathrm{Ibf})_{3}\left(\mathrm{H}_{2} \mathrm{O}\right)_{2}\right] \mathbf{3}$} & $1545(\mathrm{vs})$ & $1411(\mathrm{vs})$ & 134 \\
{$\left[\mathrm{Eu}_{2}(\mathrm{Ibf})_{6}(\mathrm{bpy})_{2}\right] \mathbf{4}$} & $1555(\mathrm{~s}) ; 1580(\mathrm{~m})$ & $1426(\mathrm{~s}) ; 1402(\mathrm{vs})$ & $129 ; 178$ \\
{$\left[\mathrm{~Tb}_{2}(\mathrm{Ibf})_{6}(\mathrm{bpy})_{2}\right] \mathbf{5}$} & $1555(\mathrm{~s}) ; 1580(\mathrm{~m})$ & $1426(\mathrm{~s}) ; 1402(\mathrm{vs})$ & $129 ; 178$ \\
{$\left[\mathrm{Gd}_{2}(\mathrm{Ibf})_{6}(\mathrm{bpy})_{2}\right] \mathbf{6}$} & $1555(\mathrm{~s}) ; 1580(\mathrm{~m})$ & $1426(\mathrm{~s}) ; 1402(\mathrm{vs})$ & $129 ; 178$ \\
{$\left[\mathrm{Eu}_{2}(\mathrm{Ibf})_{6}(\mathrm{phen})_{2}\right] \mathbf{7}$} & $1553(\mathrm{~s}) ; 1579(\mathrm{~m})$ & $1425(\mathrm{vs}) ; 1402(\mathrm{vs})$ & $128 ; 182$ \\
{$\left[\mathrm{~Tb}_{2}(\mathrm{Ibf})_{6}(\mathrm{phen})_{2}\right] \mathbf{8}$} & $1553(\mathrm{~s}) ; 1579(\mathrm{~m})$ & $1425(\mathrm{vs}) ; 1402(\mathrm{vs})$ & $128 ; 182$ \\
{$\left[\mathrm{Gd}_{2}(\mathrm{Ibf})_{6}(\mathrm{bpy})_{2}\right] \mathbf{9}$} & $1553(\mathrm{~s}) ; 1579(\mathrm{~m})$ & $1425(\mathrm{vs}) ; 1402(\mathrm{vs})$ & $128 ; 182$ \\
\hline
\end{tabular}

* (Abbreviations: (vs)=very strong; $(\mathrm{s})=$ strong; $(\mathrm{m})=$ medium; sym=symmetric; asym $=$ asymmetric).

Table 2

Mass loses observed in each TGA curves of the Ibuprofen compounds.

\begin{tabular}{|c|c|c|c|c|}
\hline Compounds & & First & Second & Residue \\
\hline$\left[\mathrm{Eu}(\mathrm{Ibf})_{3}\left(\mathrm{H}_{2} \mathrm{O}\right)_{2}\right] \mathbf{1}$ & $\begin{array}{l}(\Delta m)_{\exp } / \% \\
(\Delta m)_{\text {calc }} / \%\end{array}$ & $\begin{array}{l}4.50 \\
4.48\end{array}$ & $\begin{array}{l}73.72 \\
73.61\end{array}$ & $\begin{array}{l}21.78 \\
21.90\end{array}$ \\
\hline$\left[\mathrm{Gd}(\mathrm{Ibf})_{3}\left(\mathrm{H}_{2} \mathrm{O}\right)_{2}\right] \mathbf{2}$ & $\begin{array}{l}(\Delta m)_{\exp } / \% \\
(\Delta m)_{\text {calc }} / \%\end{array}$ & $\begin{array}{l}4.39 \\
4.45\end{array}$ & $\begin{array}{l}74.15 \\
73.06\end{array}$ & $\begin{array}{l}21.45 \\
22.39\end{array}$ \\
\hline$\left[\mathrm{Tb}(\mathrm{Ibf})_{3}\left(\mathrm{H}_{2} \mathrm{O}\right)_{2}\right] 3$ & $\begin{array}{l}(\Delta m)_{\exp } / \% \\
(\Delta m)_{\text {calc }} / \%\end{array}$ & $\begin{array}{l}4.29 \\
4.44\end{array}$ & $\begin{array}{l}73.22 \\
72.97\end{array}$ & $\begin{array}{l}22.48 \\
22.57\end{array}$ \\
\hline$\left[E u_{2}(I b f)_{6}(b p y)_{2}\right] \mathbf{4}$ & $\begin{array}{l}(\Delta m)_{\exp } / \% \\
(\Delta m)_{\text {calc }} / \%\end{array}$ & $\begin{array}{l}16.40 \\
16.88\end{array}$ & $\begin{array}{l}64.12 \\
63.97\end{array}$ & $\begin{array}{l}19.48 \\
18.92\end{array}$ \\
\hline$\left[G d_{2}(I b f)_{6}(b p y)_{2}\right] \mathbf{5}$ & $\begin{array}{l}(\Delta m)_{\exp } / \% \\
(\Delta m)_{\text {calc }} / \%\end{array}$ & $\begin{array}{l}16.35 \\
16.79\end{array}$ & $\begin{array}{l}63.81 \\
63.63\end{array}$ & $\begin{array}{l}19.84 \\
19.57\end{array}$ \\
\hline$\left[T b_{2}(\mathrm{Ibf})_{6}(\mathrm{bpy})_{2}\right] \mathbf{6}$ & $\begin{array}{l}(\Delta m)_{\exp } / \% \\
(\Delta m)_{\text {calc }} / \%\end{array}$ & $\begin{array}{l}17.9 \\
17.25\end{array}$ & $\begin{array}{l}62.73 \\
63.56\end{array}$ & $\begin{array}{l}19.37 \\
20.06\end{array}$ \\
\hline$\left[E u_{2}(I b f)_{6}(\text { phen })_{2}\right] 7$ & $\begin{array}{l}(\Delta m)_{\exp } / \% \\
(\Delta m)_{\text {calc }} / \%\end{array}$ & $\begin{array}{l}18.91 \\
19.05\end{array}$ & $\begin{array}{l}62.20 \\
62.35\end{array}$ & $\begin{array}{l}18.89 \\
18.44\end{array}$ \\
\hline$\left[G d_{2}(\operatorname{Ibf})_{6}(\text { phen })_{2}\right] \mathbf{8}$ & $\begin{array}{l}(\Delta m)_{\exp } / \% \\
(\Delta m)_{\text {calc }} / \%\end{array}$ & $\begin{array}{l}18.83 \\
18.95\end{array}$ & $\begin{array}{l}61.31 \\
62.02\end{array}$ & $\begin{array}{l}19.77 \\
19.08\end{array}$ \\
\hline$\left[\mathrm{Tb}_{2}(\mathrm{Ibf})_{6}(\text { phen })_{2}\right] \mathbf{9}$ & $\begin{array}{l}(\Delta m)_{\exp } / \% \\
(\Delta m)_{\text {calc }} / \%\end{array}$ & $\begin{array}{l}18.26 \\
18.93\end{array}$ & $\begin{array}{l}61.53 \\
61.96\end{array}$ & $\begin{array}{l}20.21 \\
19.58\end{array}$ \\
\hline
\end{tabular}

\section{Results and discussion}

From the reaction between $\mathrm{LnCl}_{3} \cdot 6 \mathrm{H}_{2} \mathrm{O}(\mathrm{Ln}=\mathrm{Eu}, \mathrm{Tb}$ and $\mathrm{Gd})$, Ibuprofen (Ibf), 2,2'-bipyridine (bpy) and 1,10-phenanthroline (phen) in 1:3:1 molar quantities, using the conventional agitation method, nine new Ibuprofen complexes were obtained: three mononuclear of general formula $\left[\mathrm{Ln}(\mathrm{Ibf})_{3}\left(\mathrm{H}_{2} \mathrm{O}\right)_{2}\right](\mathbf{1}-\mathbf{3})$ and six binuclear of general formula $\left[\operatorname{Ln}_{2}(I b f)_{6}(L N)_{2}\right](\mathbf{4 - 9})$ (with $L N=$ bpy or phen). Elemental analysis data of $\mathrm{C}, \mathrm{H}$ and $\mathrm{N}$ and complexometric titrations for the $\mathrm{Ln}^{\mathrm{III}}$ ions, indicates the $(1: 3: 2) /\left(\mathrm{Ln}^{\mathrm{III}}: \mathrm{Ibf}\right.$ : $\left.\mathrm{H}_{2} \mathrm{O}\right)$ stoichiometric proportion for the $\left[\mathrm{Ln}(\mathrm{Ibf})_{3}\left(\mathrm{H}_{2} \mathrm{O}\right)_{2}\right](\mathbf{1}-\mathbf{3})$ compounds and $(1: 3: 1) /\left(\operatorname{Ln}^{\text {III }}: \mathrm{Ibf}: \mathrm{LN}\right)$ for the $\left[\operatorname{Ln}_{2}(\operatorname{Ibf})_{6}(L N)_{2}\right](\mathbf{4 - 9})$ compounds, that is the same stoichiometric proportion used in the synthetic procedure.

All these complexes were still characterized by vibrational spectroscopy (FTIR), thermogravimetric analysis (TGA), diffuse reflectance spectroscopy (DR), X-ray diffraction patterns (PXRD), 
a

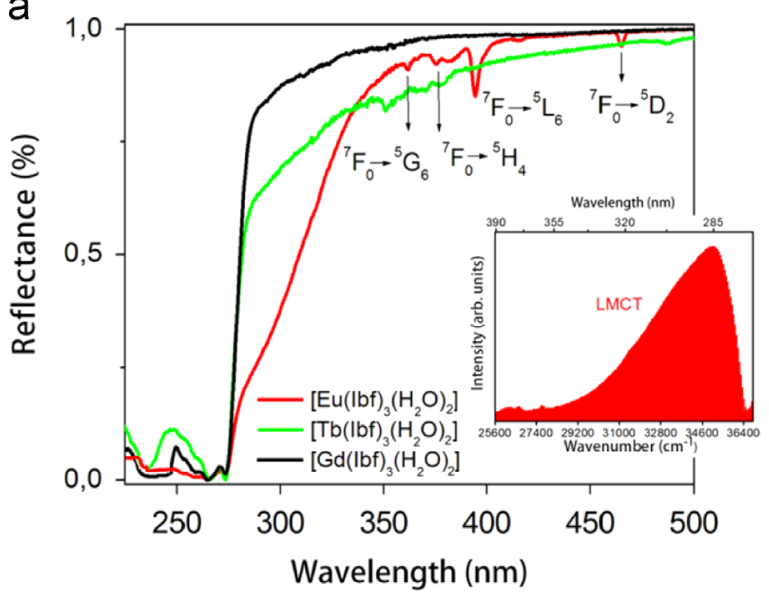

b

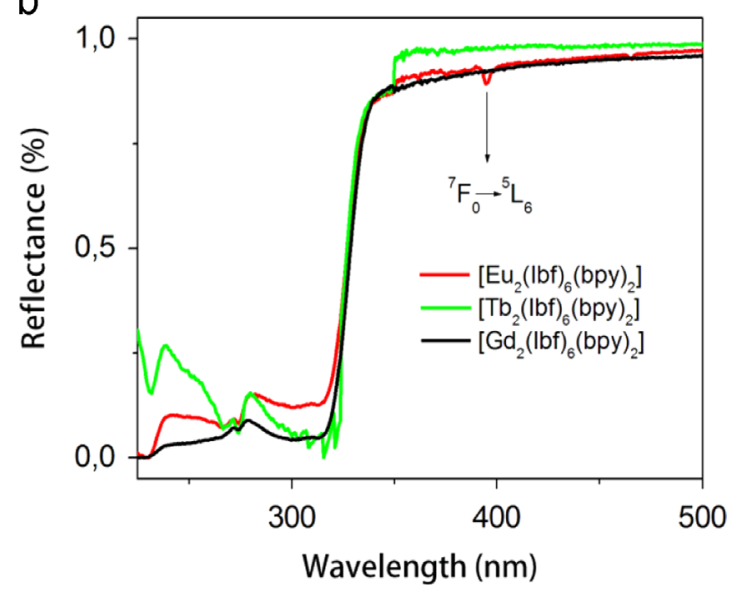

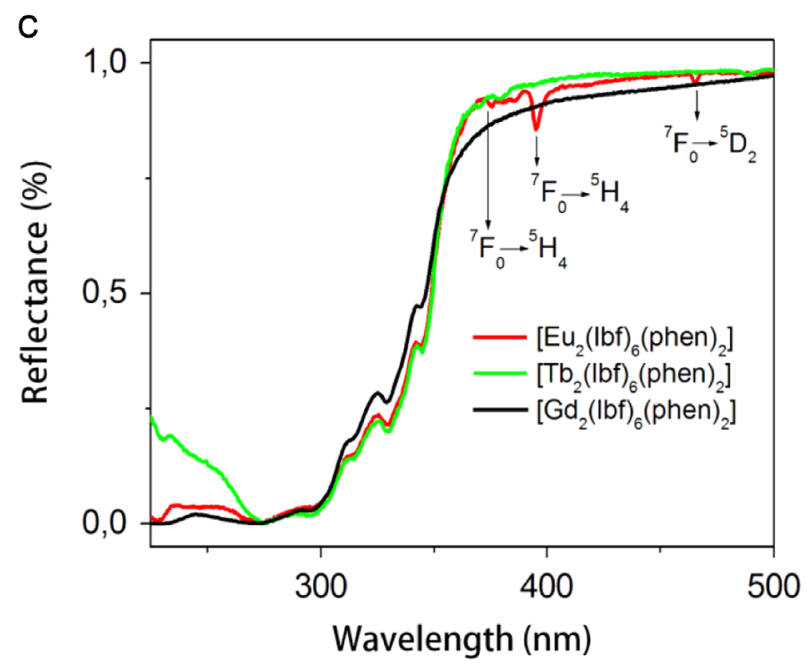

Fig. 3. UV-vis diffuse reflectance spectra of the $\mathrm{Eu}^{\mathrm{III}}, \mathrm{Gd}^{\mathrm{III}}$ and $\mathrm{Tb}^{\mathrm{III}}$ complexes. (a) $\left[\operatorname{Ln}(\mathrm{Ibf})_{3}\left(\mathrm{H}_{2} \mathrm{O}\right)_{2}\right](\mathbf{1}-\mathbf{3})$. (b) $\left[\mathrm{Ln}_{2}(\mathrm{Ibf})_{6}(b p y)_{2}\right](\mathbf{4}-\mathbf{6})$. (c) $\left[\mathrm{Ln} n_{2}(\mathrm{Ibf})_{6}(\mathrm{phen})_{2}\right](\mathbf{7}-\mathbf{9})$.

excitation/emission spectra and luminescence decay curves. The $\mathrm{Eu}^{\mathrm{III}}$ complexes structures were also calculated using the RM1 model for lanthanide complexes and the spectroscopic properties as: $\Omega_{\lambda}$ intensity parameters ( $\lambda=2,4$ and 6$)$, energy transfer $\left(W_{\mathrm{ET}}\right)$ and back-transfer $\left(\mathrm{W}_{\mathrm{BT}}\right)$ rates, radiative $\left(A_{\mathrm{rad}}\right)$ and nonradiative $\left(A_{\text {nrad }}\right)$ decay rates and quantum efficiency $(\eta)$ calculated from the experimental data and from RM1 model.

\subsection{X-ray powder diffraction data}

Numerous attempts to grow single crystals for the complexes 1-9 from several solvents solutions were not fruitful. Thus, polycrystalline X-ray diffraction patterns (PXRD) were obtained for: $\left[\mathrm{Ln}_{2}(\mathrm{Ibf})_{6}(\mathrm{bpy})_{2}\right](\mathbf{4}, \mathbf{5}$ and $\mathbf{6})$ and $\left[\mathrm{Ln}_{2}(\mathrm{Ibf})_{6}(\text { phen })_{2}\right]$ (7 and 9), with the complexes $\left[\mathrm{Ln}(\mathrm{Ibf})_{3}\left(\mathrm{H}_{2} \mathrm{O}\right)_{2}\right](\mathbf{1}, \mathbf{2}$ and $\mathbf{3})$ and $\left[\mathrm{Gd}_{2}(\mathrm{Ibf})_{6}(\mathrm{phen})_{2}\right] \mathbf{8}$ being amorphous. From PXRD patterns exhibited in Fig. $1 a$ and $b$, high crystallinity can be noticed for the five complexes. These data show that complexes 4, 5 and $\mathbf{6}$ form a class isostructural, with the same occurring for the compounds $\mathbf{7}$ and $\mathbf{9}$. Taking into account the isostructural $\left[\operatorname{Ln}_{2}(I b f)_{6}(b p y)_{2}\right]$ (4-6) complexes, the approximate unit cell parameters were found by 21 first standard peaks using $\left[\mathrm{Tb}_{2}(\mathrm{Ibf})_{6}(\mathrm{bpy})_{2}\right] \mathbf{6}$ data, followed by indexing through the single-value decomposition approach [46] implemented in TOPAS [47] and analyses of translation lattice and cell reduction were check out. The space group $P-1$ was chosen and the cell parameters were refined using 6-55, 2 theta range by Pawley method [48] giving the good $R_{\mathrm{wps}}=2.53,2.50$ and 2.10 for $\mathrm{Eu}^{\mathrm{III}}, \mathrm{Gd}^{\mathrm{III}}$ complexes and $\mathrm{Tb}^{\mathrm{III}}$ respectively and no higher symmetric system was suggested by PLATON [49]. Then the structure solution processes were tried by the simulated annealing technique [50] and the Ibf ligand rigid body model, based on single-crystal data [51] was built using Cartesian Coordinates with free rotations and translations as well torsion angles while 2,2'-bipyridine rigid body was idealized by $\mathrm{Z}$ matrix formalism as described in our previously manuscript [52] and metal ions were left free. It is important to note that the powder diffraction state-of-art has limitations concerning on number of parameter in the simulated annealing (SA), needless to say, by our few experience the SA procedure become unstable over than 25 parameters and in the present cases, each structure has 1 for scale, 3 translations (for metals ion); 3 translation, 3 rotation; (2,2'-bipyridine) and 3 translation; 3 rotation and 4 torsion angle (for each Ibf ion), making 40 parameters. Therefore, even our exhausting efforts at least for three months, time computation and our knowledge in solving complicated structures using X-ray powder diffraction data $[12,53,54]$ no plausible crystallographic solutions were found, unfortunately.

\subsection{Infrared spectroscopy}

The infrared spectra of the synthesized complexes and Ibuprofen sodium salt (NaIbf) are displayed in Fig. 2. The similarity of the lanthanide complexes IR spectra indicates the formation of three classes of isostructural compounds: $\left[\mathrm{Ln}(\mathrm{Ibf})_{3}\left(\mathrm{H}_{2} \mathrm{O}\right)_{2}\right](\mathbf{1}-\mathbf{3})$, $\left[\mathrm{Ln}_{2}(\mathrm{Ibf})_{6}(\mathrm{bpy})_{2}\right](\mathbf{4 - 6})$ and $\left[\mathrm{Ln}_{2}(\mathrm{Ibf})_{6}(\text { phen })_{2}\right]($ 7-9) ( $\mathrm{Ln}=\mathrm{Eu}, \mathrm{Gd}$ and $\mathrm{Tb})$, as have been proved by X-ray diffraction analysis results for the $\left[\operatorname{Ln}_{2}(I b f)_{6}(b p y)_{2}\right]$ and $\left[\operatorname{Ln}_{2}(I b f)_{6}(\text { phen })_{2}\right]$ compounds. In this class 
a

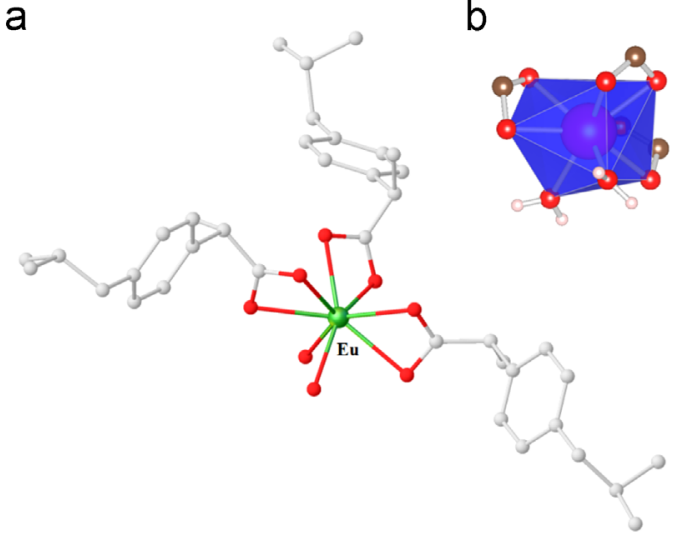

C

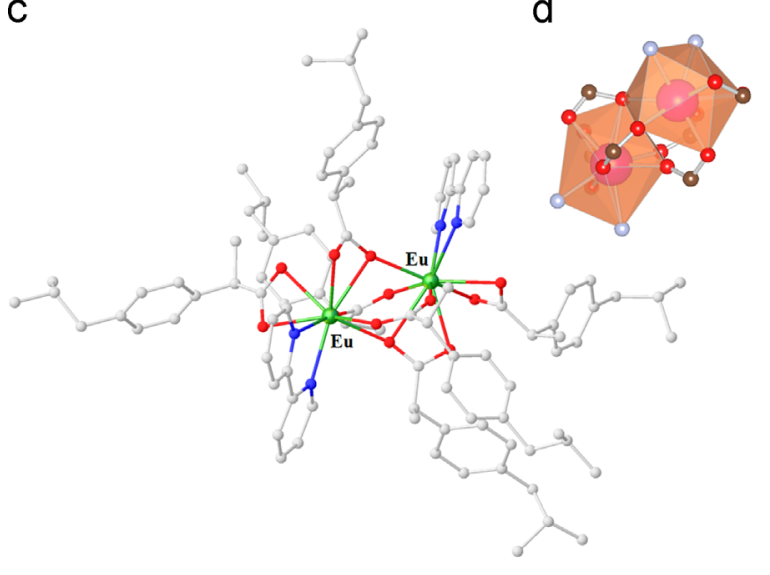

e

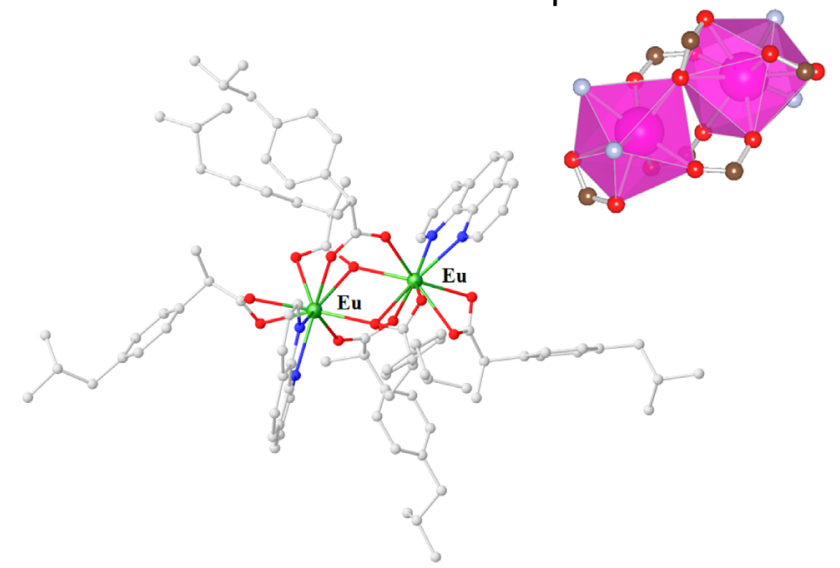

Fig. 4. (a) Ground state geometry for the complexes $\left[\mathrm{Eu}(\mathrm{Ibf})_{3}\left(\mathrm{H}_{2} \mathrm{O}\right)_{2}\right] \mathbf{1}$ $\left[E u_{2}(I b f)_{6}(\text { bpy })_{2}\right] \mathbf{4}$ and $\left[E u_{2}(I b f)_{6}(\text { phen })_{2}\right] \mathbf{7}$ calculated by the RM1 model and drawn using OLEX [57] program. The hydrogen atoms were omitted for clarity. Coordination polyhedra formed by units $\left[\mathrm{EuO}_{8}\right]$ in $\mathbf{1}$ and $\left[\mathrm{EuO}_{6} \mathrm{~N}_{2}\right]$ in $\mathbf{4}$ and $\mathbf{7}$ are shown in (b, d and f) and they are connected through Ibf anions in the binuclear compounds. Color codes: C, light - gray; O, red; N, blue and Eu, green. (For interpretation of the references to color in this figure legend, the reader is referred to the web version of this article.)

of compounds, the difference $(\Delta \nu)$ between $\nu_{\text {asym }}\left(\mathrm{COO}^{-}\right)$and $\nu_{\text {sym }}\left(\mathrm{COO}^{-}\right)$in comparison to the corresponding values in ionic species is currently employed to propose the carboxylate group coordination mode [55]. This is an important tool, since lanthanide carboxylates usually contain a variety of different coordination modes as a result of their large coordination numbers. The $\Delta \nu$ values calculated for the sodium salt ligand and the respective complexes series are shown in Table 1. a<smiles></smiles>

b<smiles>CCCCCCCCC(=O)OC(=O)C(C)c1ccc(CC(C)C)cc1</smiles>

C<smiles>CC(C)Cc1ccc([C@@H](C)C2=[GeH][AlH]O2)cc1</smiles>

Chart 2. Coordination modes of the carboxylate group in binuclear Ibuprofen compounds.

The coordination of the $\mathrm{COO}^{-}$group was confirmed by the shift of the $\nu_{\text {asym }}\left(\mathrm{COO}^{-}\right)$stretching to lower wavenumbers in the FTIR spectra of the compounds when compared with the Ibuprofen sodium salt (Fig. 2, Table 1). The bands attributed to the $\mathrm{COO}^{-}$ group for Ibuprofen sodium salt are centered at $1587 \mathrm{~cm}^{-1}$ (asymmetric stretching) and $1405 \mathrm{~cm}^{-1}$ for the symmetric stretching, providing $\Delta \nu=182 \mathrm{~cm}^{-1}$. For the $\left[\mathrm{Ln}(\mathrm{Ibf})_{3}\left(\mathrm{H}_{2} \mathrm{O}\right)_{2}\right](\mathbf{1}-\mathbf{3})$ complexes (Fig. 2a) the bands attributed to $\nu_{\text {asym }}\left(\mathrm{COO}^{-}\right)$and $\nu_{\text {sym }}\left(\mathrm{COO}^{-}\right)$vibrational modes appears at $1545 \mathrm{~cm}^{-1}$ and $1411 \mathrm{~cm}^{-1}$, respectively. These data provide the $\Delta \nu$ value of $134 \mathrm{~cm}^{-1}$, suggesting that Ibuprofen coordinates through the carboxylate group as a bidentate chelating ligand. In the $\left[\operatorname{Ln}_{2}(\mathrm{Ibf})_{6}(\mathrm{bpy})_{2}\right]$ (4-6) (Fig. 2b) and $\left.\left[\operatorname{Ln}_{2}(\mathrm{Ibf})_{6} \text { (phen }\right)_{2}\right]$ (7-9) (Fig. 2c) complexes there is a splitting of the bands attributed to the $\nu_{\text {asym }}\left(\mathrm{COO}^{-}\right)$and $\nu_{\text {sym }}\left(\mathrm{COO}^{-}\right)$vibrational modes (Table 1 ) providing two $\Delta \nu$ values for each complex, in accordance with two different coordination modes of the carboxylate groups; bidentate bridging and chelate modes [9,12]. Additionally, the $\mathrm{C}=\mathrm{N}$ stretching frequencies in the free bpy $\left(1592 \mathrm{~cm}^{-1}\right)$ and phen $\left(1598 \mathrm{~cm}^{-1}\right.$ ) spectra (not shown), are shifted to higher wavenumbers (1605 and $1604 \mathrm{~cm}^{-1}$ ) in [ $\left.\operatorname{Ln}_{2}(\mathrm{Ibf})_{6}(\mathrm{bpy})_{2}\right]$ (4-6) and $\left[\mathrm{Ln}_{2}(\mathrm{Ibf})_{6}(\text { phen })_{2}\right]$ (7-9) complexes, respectively. This indicates the $\mathrm{N}, \mathrm{N}$-donors ligands coordination to the lanthanide centers through the pyridine nitrogen atom, as observed for previous structurally characterized compounds containing pyridil rings $[9,12]$.

\subsection{Thermal analysis}

Thermal behavior, particular stability and volatility, is important for practical applications in luminescent materials. The thermogravimetric analysis (TGA) was carried out using 1-9 samples in the temperature range of $30-800{ }^{\circ} \mathrm{C}$ under nitrogen atmosphere. The thermogravimetric results for the studied compounds are shown in Table 2, while de TG curves are shown in Figs. S1-S3 in Supplementary material. In recent study, Gálico et al. [13] presented a complete thermal study of compounds with the general formula $\mathrm{LnL}_{3}$ ( $L=$ Ibuprofen ligand and $\mathrm{Ln}=\mathrm{La}, \mathrm{Ce}, \mathrm{Pr}, \mathrm{Nd}, \mathrm{Sm}$ and $\mathrm{Eu})$. The $\left[\mathrm{Ln}(\mathrm{Ibf})_{3}\left(\mathrm{H}_{2} \mathrm{O}\right)_{2}\right]$ (1-3) complexes studied here, present very similar TG curves to the aforementioned compounds, establishing the similar type of thermal behavior. The TG curves of these compounds (Fig. S1) show the first small weight loss between 30 and $152{ }^{\circ} \mathrm{C}$ corresponding to the release of two coordinated water molecules per formula unit. Two consecutive mass losses can be observed from 197 to $345{ }^{\circ} \mathrm{C}$, and $345^{\circ} \mathrm{C}$ to $524{ }^{\circ} \mathrm{C}$ and are ascribed to the decomposition of organic moiety. The binuclear compounds $\left[\mathrm{Ln}_{2}(\mathrm{Ibf})_{6}(\mathrm{bpy})_{2}\right](\mathbf{4 - 6})$ and $\left[\operatorname{Ln}_{2}(\mathrm{Ibf})_{6}(\mathrm{phen})_{2}\right](\mathbf{7 - 9})$ exhibit similar thermal behavior when compared with their congeners, as expected. All these compounds are stable up to $120^{\circ} \mathrm{C}$ (for 4-6) and $236{ }^{\circ} \mathrm{C}$ (for 7-9), indicating the absence of water molecules in 


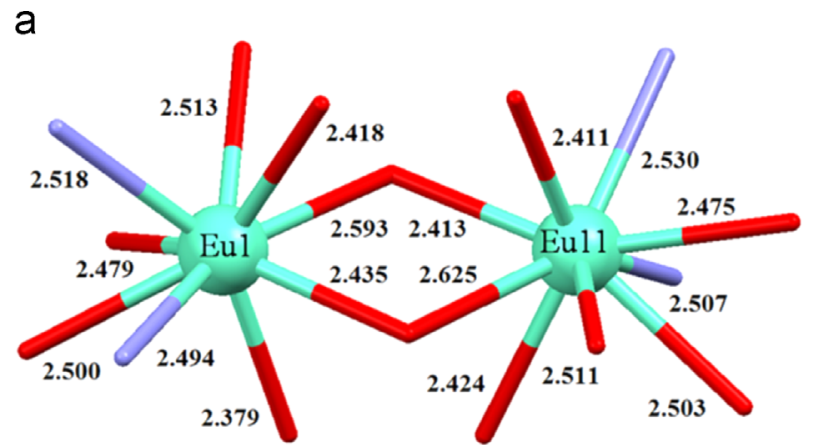<smiles>CC(C)Cc1ccc(C(C)C(=O)O)cc1</smiles>
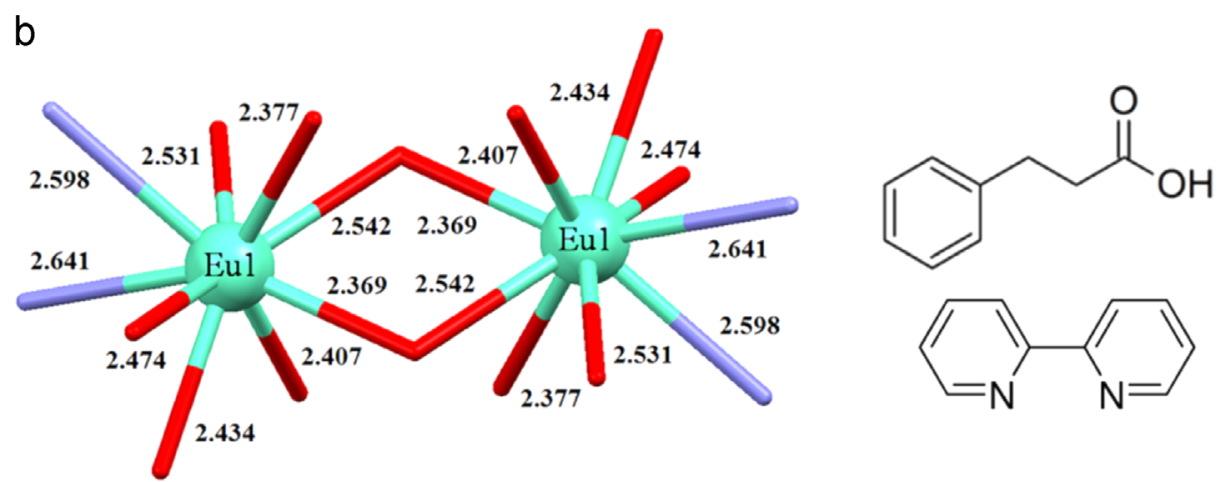

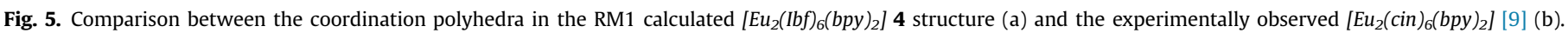
Color codes: $\mathrm{O}$, red; $\mathrm{N}$, blue and Eu, green. (For interpretation of the references to color in this figure legend, the reader is referred to the web version of this article.)

their structures. The $\left[\operatorname{Ln}_{2}(\mathrm{Ibf})_{6}(\mathrm{bpy})_{2}\right]$ (4-6) compounds (Fig. S2) present the first mass losses, between 120 to $215^{\circ} \mathrm{C}$, attributed to release of two bpy ligands. Afterwards, between 386 and $586{ }^{\circ} \mathrm{C}$, the mass losses are consistent with the decomposition of approximately six Ibuprofen ligands. For the $\left[\mathrm{Ln}_{2}(\mathrm{Ibf})_{6}(\mathrm{phen})_{2}\right]$ (7-9) complexes (Fig. S3), the same thermal behavior is observed, with the first mass losses $\left(236\right.$ to $384^{\circ} \mathrm{C}$ ) being attributed to two phen ligands, and consecutively, between 384 and $498{ }^{\circ} \mathrm{C}$ to release of six Ibuprofen ligands. In all cases, at $800^{\circ} \mathrm{C}$, the residual percentage weight is consistent with the lanthanide oxides. Table 2 shows a comparison between experimental and calculated weight loss $(\Delta m)$ for the complexes 1-9.

\subsection{Diffuse reflectance (DR) spectroscopy}

In the absorption spectra of solutions, the solvent effect makes it difficult to study the complexes energy levels. This difficulty can be overcome by studying the diffuse reflectance spectra, allowing the identification of the ligand centered as well as the sharp $4 \mathrm{f}-4 \mathrm{f}$ transitions. DR spectra of the synthesized complexes are shown in Fig. 3a-c while for the Ibuprofen ligand is shown in Fig. S4 (Supplementary material). The Ibuprofen ligand presents a wide and intense band in the UV region $(200-275 \mathrm{~nm})$ that can be attributed to electronic transition from the ground-state level $(\pi)$ $\mathrm{S}_{0}$ to the excited level $\left(\pi^{*}\right) \mathrm{S}_{1}$. The spectra of $\left[\operatorname{Ln}(\mathrm{Ibf})_{3}\left(\mathrm{H}_{2} \mathrm{O}\right)_{2}\right](\mathbf{1}-\mathbf{3})$ complexes (Fig. 3a) also presents this wide and intense absorption band, which in the case of $\left[\operatorname{Ln}_{2}(\mathrm{Ibf})_{3}(b p y)_{2}\right]($ 4-6) (Fig. 3b) and $\left[\mathrm{Ln}_{2}(\mathrm{Ibf})_{6}(\text { phen })_{2}\right]$ (7-9) (Fig. 3c) compounds are extended to $350 \mathrm{~nm}$ and clearly confirms the coordination of the Ibuprofen ligand in the synthesized $\mathrm{Ln}^{\mathrm{III}}$ complexes. In order to investigate a possible ligand-to-metal charge transfer (LMCT) in the complexes, the diffuse reflectance spectra of Eu ${ }^{\text {III }}$ complexes were compared with the isostructural $\mathrm{Gd}^{\mathrm{III}}$ compounds. It is known, once that the $\mathrm{Gd}^{\mathrm{III}}$ excited levels lie much higher than the typical energy of the ligand triplet states, disabling any LMCT process [56]. The LMCT band was obtained by the arithmetic subtraction between two spectra (inset in Fig. 3a) and observed only for the [ $\mathrm{Eu}(\mathrm{Ibf})_{3}\left(\mathrm{H}_{2} \mathrm{O}\right)_{2}$ ] 1 complex. Characteristic absorption bands due to transitions from ground-state to excited states in the complexes containing $\mathrm{Eu}^{\mathrm{III}}$ ion are also observed. Peaks at 362, 378, 394 and $464 \mathrm{~nm}$ were assigned to ${ }^{7} \mathrm{~F}_{0} \rightarrow{ }^{5} \mathrm{G}_{6},{ }^{7} \mathrm{~F}_{0} \rightarrow{ }^{5} \mathrm{H}_{4},{ }^{7} \mathrm{~F}_{0} \rightarrow{ }^{5} \mathrm{~L}_{6}$ and ${ }^{7} \mathrm{~F}_{0} \rightarrow{ }^{5} \mathrm{D}_{2}$ transitions. In $\mathrm{Tb}^{\text {III }}$ complexes the broad absorption band attributed to Ibuprofen ligand overlaps some absorption bands corresponding to the characteristic transitions of $\mathrm{Tb}^{\mathrm{III}}$ ions, such as ${ }^{7} \mathrm{~F}_{6} \rightarrow{ }^{5} \mathrm{~L}_{8}$, ${ }^{7} \mathrm{~F}_{6} \rightarrow{ }^{5} \mathrm{~L}_{9}$ and ${ }^{7} \mathrm{~F}_{6} \rightarrow{ }^{5} \mathrm{G}_{5}$.

\subsection{Molecular structures of the Eu ${ }^{I I I}$ complexes by RM1 model}

Due to the lack samples appropriate for single crystal X-ray analysis, we lay hold of quantum chemical calculations available to shed light onto the molecular structure of the $\mathrm{Eu}^{\mathrm{III}}$ Ibuprofen complexes, once that the geometry knowledge is fundamental to predict spectroscopic properties as well as singlet and triplet energy positions posteriorly discussed in this work. All characterization results discussed above are in excellent agreement with the optimized structures, which was further proved with the fitting of the theoretically calculated Judd-Ofelt parameters with those that had been experimentally observed. The optimized ground state geometries of the Eu ${ }^{\mathrm{III}}$ Ibuprofen complexes 1, 4 and 7 are depicted in Fig. $4 a-c$.

In the mononuclear complex $\mathbf{1}$, the $\mathrm{Eu}^{\mathrm{III}}$ ion are coordinated to three ibuprofenate anions and two coordinated water molecules, resulting in a coordination number equal to eight (Fig. 4a). The coordination geometry of the Eu ${ }^{\text {III }}$ is well described as a distorted dicapped trigonal prism (Fig. 4b). The obtained molecular structure for $\left[\mathrm{Eu}(\mathrm{Ibf})_{3}\left(\mathrm{H}_{2} \mathrm{O}\right)_{2}\right] \mathbf{1}$ (Fig. 3a), is similar to those observed for the $\left[\mathrm{Eu}(\mathrm{Ibf})_{3}\right] .1 .5 \mathrm{H}_{2} \mathrm{O}$, reported recently by Gálico et al. [13], where the authors suggests the presence of lattice water molecules in the compound, with the $\mathrm{Eu}^{\mathrm{III}}$ ion having a coordination number equal to six, not common for monocarboxylates of lanthanides. Contradicting this fact, we believe that in our compound at least two water molecules act as ligands completing the coordination sphere 

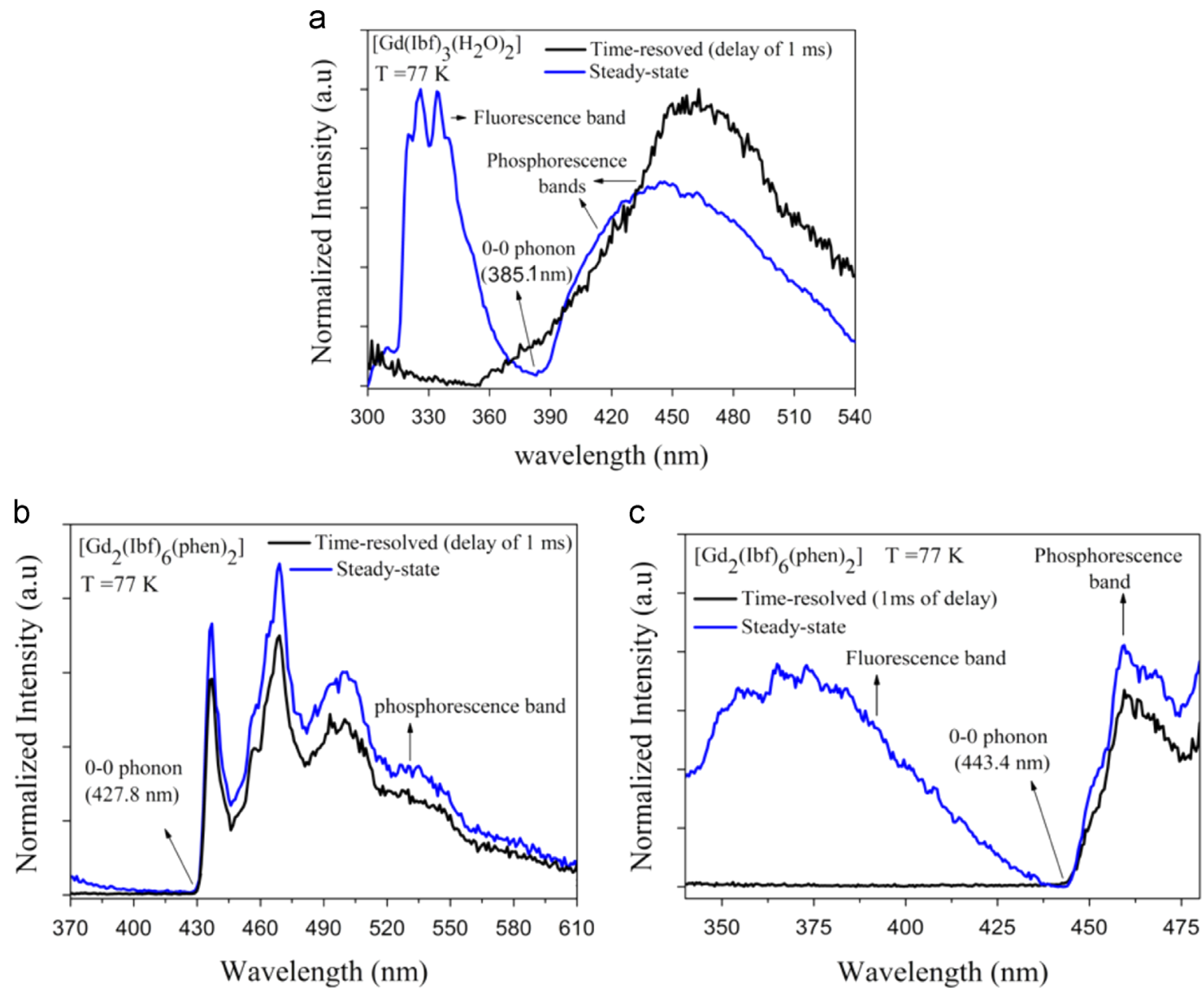

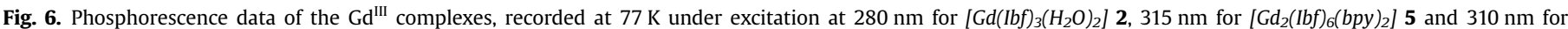

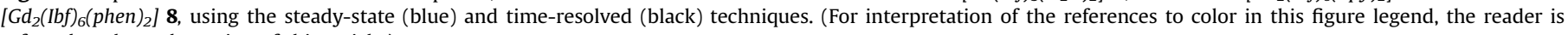
referred to the web version of this article.)

of the lanthanide centers in compounds 1-3, as discussed later in the photoluminescence study. A similar fact to this is observed in the literature, where the authors suggests the formula $\mathrm{Eu}(\mathrm{L})_{3} \cdot \mathrm{H}_{2} \mathrm{O}$ ( $\mathrm{L}=$ Ketoprofen) for the lanthanide complex, with one lattice water molecule in this structure [58]. Posteriorly, making use of a photoluminescence properties study (as we will do here), the authors proved that this water molecule is directly coordinated to $\mathrm{Eu}^{\mathrm{III}}$ ion [59]. On the other hand, binuclear complexes, as the $\left[L n_{2}(I b f)_{6}(L N)_{2}\right]$ (LN=bpy 4-6 or phen 7-9 ) studied here, can be achieved when carboxylate ligands along with 2,2'-bipyridine (bpy) or 1,10-phenanthroline (phen) are used. Several examples can be found in the literature as exemplified by $\left\{\left[\mathrm{Eu}_{2}(2-\right.\right.$ $\left.\mathrm{BrBA})_{6}(\text { bpy })_{2}\right]_{2} . \mathrm{CH}_{3} \mathrm{CH}_{3} \mathrm{OH} . \mathrm{H}_{2} \mathrm{O}$ \} [60] (2BrBA=2-bromobenzoate), [Eu ${ }_{2}(3,4-D M B A)_{6}$ (phen $)_{2}$ ] [61] (3,4-DMBA=3,4-dimethylbenzoate), $\left[\mathrm{Eu}_{2}(\mathrm{cin})_{6}(\mathrm{bpy})_{2}\right][9]$ and $\left[\mathrm{Eu}_{2}(\mathrm{cin})_{6}(\text { phen })_{2}\right]$ [12] (cin=hydrocinnamate anion). In the $\left[\mathrm{Eu}_{2}(\mathrm{Ibf})_{6}(\mathrm{bpy})_{2}\right] \mathbf{4}$ (Fig. 4c) and $\left[\mathrm{Eu}_{2}(\mathrm{Ibf})_{6}(\text { phen })_{2}\right] \mathbf{7}$ (Fig. 4e), the Eu ${ }^{\mathrm{III}}$ ions are surrounded by seven oxygen atoms from ibuprofenate ligands and two nitrogen atoms from $\mathrm{N}, \mathrm{N}$-donors ligands (bpy or phen) completing the coordination number nine. The coordination geometry of the Eu ${ }^{\mathrm{III}}$ is well described as a distorted tricapped trigonal prism (Fig. $4 \mathrm{~d}$ and f). In this structures, the carboxylate groups present different coordination modes to metal centers, and in the case of the binuclear compounds 4-9 described in this study, the three coordination modes can be seen in Chart 2 .

Carboxylate oxygen atoms can act as bidentate chelating, Chart 2 (a), and, one of the oxygen atoms is coordinated to another $\mathrm{Ln}^{\mathrm{III}}$ ion forming a monoatomic bridge or $\mu$ - oxo bridge. The carboxylate group can also connect a pair of $\operatorname{Ln}^{\text {III }}$ ions in a $s y n, s y n-\eta^{1}: \eta^{1}: \mu_{2}$ bidentate bridging fashion, as depicted in Chart 2(b), In coordination mode (c), Ibf anion acts as simple bidentate chelating ligand toward one Eu ${ }^{\text {III }}$ center with two oxygen atoms from carboxylate group. Data on the synthesis and crystal structures of lanthanides complexes with Ibuprofen ligand are very scarce [13] and to the best of our knowledge, do not exist crystal structures of lanthanide complexes containing the Ibuprofen ligand. However, the calculated molecular structures for these binuclear compounds are similar to those crystal structures observed in the case of $\left[\mathrm{Eu}_{2}(\mathrm{Cin})_{6}(\mathrm{bpy})_{2}\right]$ [9] and $\left[\mathrm{Eu}_{2}(\mathrm{cin})_{6}(\text { phen })_{2}\right]$ [12] (cin=hydrocinnamate anion), recently reported by our group. The values of $\mathrm{Ln}-\mathrm{N}$ and $\mathrm{Ln}-\mathrm{O}$ bond lengths in $\left[\mathrm{Eu}_{2}(\mathrm{cin})_{6}(\mathrm{bpy})_{2}\right]$ are about 2.6 and $2.4 \AA$, respectively, and Ln-N and $\mathrm{Ln}-\mathrm{O}$ distances in calculated $\left[\mathrm{Eu}_{2}(\mathrm{Ibf})_{6}(\mathrm{bpy})_{2}\right] \mathbf{4}$ structure vary from 2.53 to 2.49 and from 2.59 to $2.37 \AA$. The Fig. 5 shows the comparison between the coordination polyhedra in the calculated $\left[\mathrm{Eu}_{2}(\mathrm{Ibf})_{6}(\mathrm{bpy})_{2}\right] \mathbf{4}$ structure in study (a) and the experimentally observed $\left[\mathrm{Eu}_{2}(\mathrm{cin})_{6}(\mathrm{bpy})_{2}\right]$ (b), confirming the suitability of RM1 model in the calculation of the ground state geometry of our complex.

Tables S1-S3 in Supplementary material, shows selected spherical atomic coordinates for coordination polyhedra of the [Eu $\left.(\mathrm{Ibf})_{3}\left(\mathrm{H}_{2} \mathrm{O}\right)_{2}\right] \mathbf{1},\left[\mathrm{Eu}_{2}(\mathrm{Ibf})_{6}(\mathrm{bpy})_{2}\right] \mathbf{4}$ and $\left[\mathrm{Eu}_{2}(\mathrm{Ibf})_{6}(\text { phen })_{2}\right] \mathbf{7}$ complexes, arising from the RM1 model. All the average Eu-O and Eu$\mathrm{N}$ predicted values obtained from RM1 model agreeing well with 

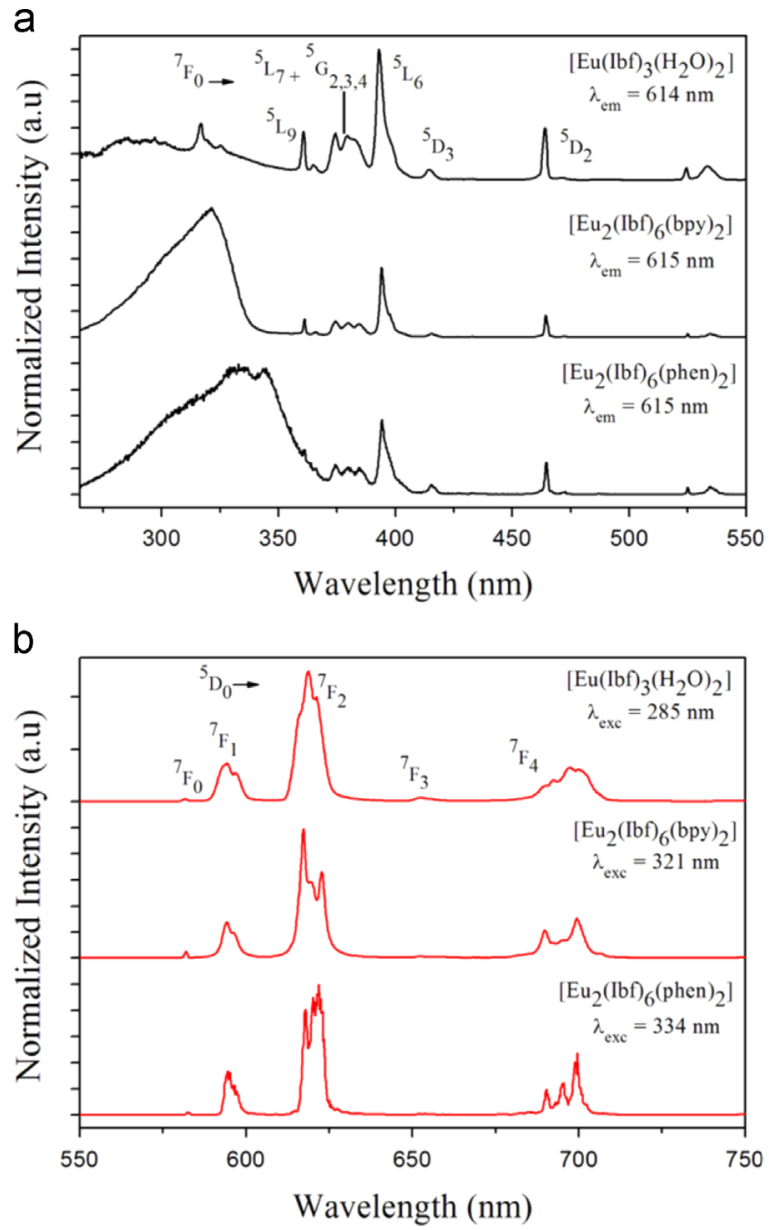

Fig. 7. (a) Excitation and (b) emission spectra of the Eu ${ }^{\mathrm{III}}$ complexes 1, 4 and 7. All the spectra were obtained in the solid state at $77 \mathrm{~K}$.

those obtained from the crystallographic studies for the similar structures reported in the literature $[9,12]$.

\subsection{Photoluminescence studies}

\subsubsection{Phosphorescence of the GdIII Ibuprofen complexes}

The emission phosphorescence spectrum for the $\mathrm{Gd}^{\mathrm{III}}$ compounds allowed the identification of the lowest ligand triplet state in the lanthanide complexes. Usually, $\mathrm{Gd}^{\mathrm{III}}$ compounds are useful for this purpose, because of their structural similarity with $\mathrm{Eu}^{\mathrm{III}}$ and $\mathrm{Tb}^{\mathrm{III}}$ complexes. In this context the larger probability of the ligand phosphorescence is due to a combination of both paramagnetic [62] and heavy-atom effects [63]. In addition, Gd ${ }^{\mathrm{III}}$ cannot provide an appropriate acceptor state for antennas in the near$\mathrm{UV} / \mathrm{vis}$ range because its first excited state $\left({ }^{6} \mathrm{P}_{7 / 2}\right)$ lies $\sim 32,000 \mathrm{~cm}^{-1}$ above its ground state. Another factor is the chemical similarity between $\mathrm{Gd}^{\mathrm{III}}$ and $\mathrm{Eu}^{\mathrm{III}}$, once that their ionic radii differ by less than $1 \%$, allowing the study of intraligand phosphorescence for a ligand topology very close that of similar Eu ${ }^{\text {III }}$ complex.

In the phosphorescence spectra (obtained at $77 \mathrm{~K}$ ), the energy of the triplet states $\left(\mathrm{T}_{1}\right)$ were determined from the $0-0$ phonon transition for the $\mathrm{Gd}^{\mathrm{III}}$ complexes. In order to determine unequivocally the energy due to the $0-0$ phonon transition for the Gd ${ }^{\text {III }}$ complexes, the time-resolved spectra are obtained. In this case, the fluorescence bands decrease very fast as the flash delay is increased and only the phosphorescence spectrum from the
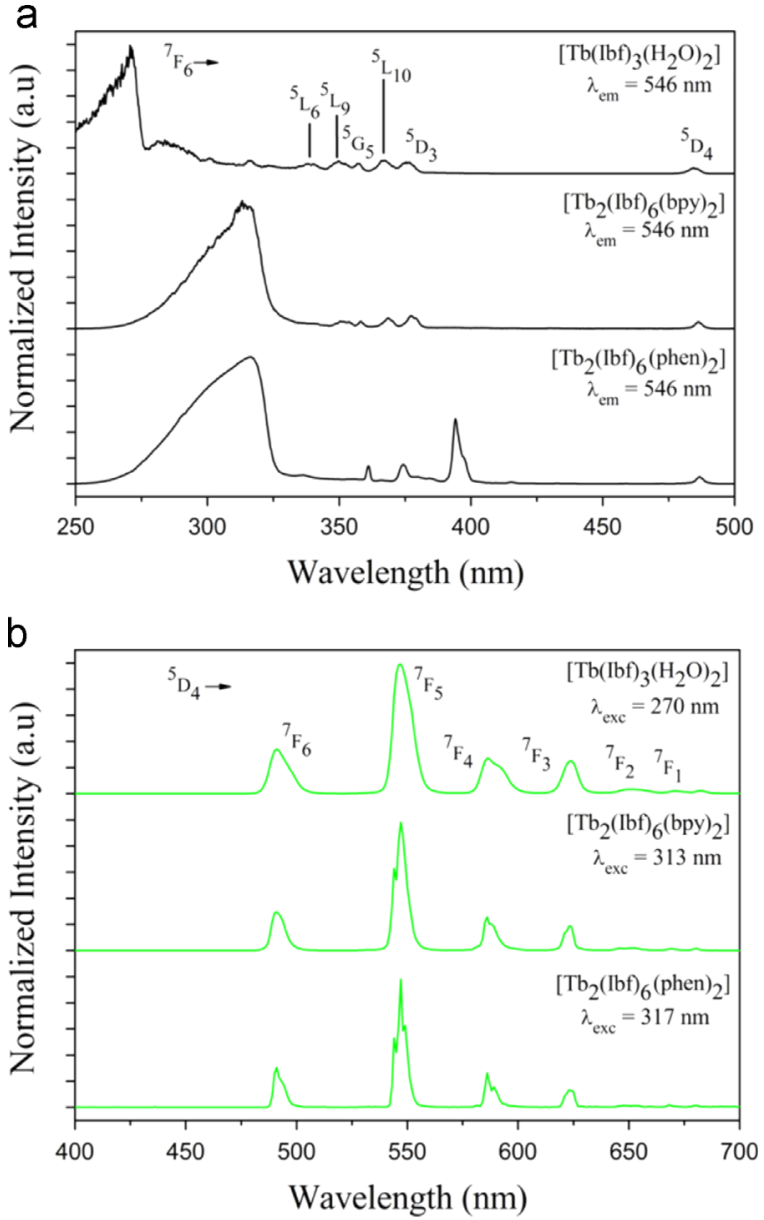

Fig. 8. (a) Excitation and (b) emission spectra of the $\mathrm{Tb}^{\mathrm{III}}$ complexes 3,6 and $\mathbf{9}$. All the spectra were obtained in the solid state at $77 \mathrm{~K}$.

Table 3

Experimental values of intensity parameters $\left(\Omega_{2}\right.$ and $\left.\Omega_{4}\right)$, radiative $\left(A_{\mathrm{rad}}\right)$ and nonradiative $\left(A_{\text {nrad }}\right)$ rates, lifetimes $(\tau)$ and emission quantum efficiencies $(\eta)$ for the Eu ${ }^{\text {III }}$ Ibuprofen complexes studied.

\begin{tabular}{llll}
\hline Parameters & {$\left[\mathrm{Eu}(\mathrm{Ibf})_{3}\left(\mathrm{H}_{2} \mathrm{O}\right)_{2}\right] \mathbf{1}$} & {$\left[\mathrm{Eu}_{2}(\mathrm{Ibf})_{6}(\mathrm{bpy})_{2}\right] \mathbf{4}$} & {$\left[\mathrm{Eu}_{2}(\mathrm{Ibf})_{6}(\text { phen })_{2}\right] \mathbf{7}$} \\
\hline$\Omega_{2} /\left(10^{-20} \mathrm{~cm}^{2}\right)$ & 7.02 & 7.73 & 8.91 \\
$\Omega_{4} /\left(10^{-20} \mathrm{~cm}^{2}\right)$ & 6.71 & 7.98 & 7.90 \\
$A_{\text {rad }}\left(\mathrm{s}^{-1}\right)$ & 361.30 & 401.12 & 430.31 \\
$A_{\text {nrad }}\left(\mathrm{s}^{-1}\right)$ & $1,226.00$ & 176.92 & 101.61 \\
$\tau(\mathrm{ms})$ & 0.63 & 1.73 & 1.88 \\
$\eta(\%)$ & 22.76 & 69.39 & 80.90 \\
\hline
\end{tabular}

* $\left(\Omega_{6}\right.$ parameter could not be estimated, once that the ${ }^{5} \mathrm{D}_{0} \rightarrow{ }^{7} \mathrm{~F}_{6}$ not is observed)

Table 4

Theoretical intensity parameters $\Omega_{2}, \Omega_{4}$ and $\Omega_{6}$, radiative $\left(A_{\mathrm{rad}}\right)$ and nonradiative $\left(A_{\text {nrad }}\right.$ ) decay rates quantum efficiency $(\eta)$ and quantum yield $(q)$ values derived from the optimized RM1 model.

\begin{tabular}{llll}
\hline $\begin{array}{l}\text { Parameters RM1 } \\
\text { model }\end{array}$ & {$\left[\mathrm{Eu}(\mathrm{Ibf})_{3}\left(\mathrm{H}_{2} \mathrm{O}\right)_{2}\right] \mathbf{1}$} & {$\left[\mathrm{Eu}_{2}(\mathrm{Ibf})_{6}(\mathrm{bpy})_{2}\right] \mathbf{4}$} & {$\left[\mathrm{Eu}_{2}(\mathrm{Ibf})_{6}(\mathrm{phen})_{2}\right] \mathbf{7}$} \\
\hline$\Omega_{2} /\left(10^{-20} \mathrm{~cm}^{2}\right)$ & 8.28 & 7.73 & 8.91 \\
$\Omega_{4} /\left(10^{-20} \mathrm{~cm}^{2}\right)$ & 2.45 & 7.97 & 7.90 \\
$\Omega_{6} /\left(10^{-20} \mathrm{~cm}^{2}\right)$ & 0.08 & 0.08 & 0.09 \\
$A_{\text {rad }}\left(\mathrm{s}^{-1}\right)$ & 334.91 & 402.19 & 436.54 \\
$A_{\text {nrad }}\left(\mathrm{s}^{-1}\right)$ & 1252.39 & 175.85 & 95.38 \\
$\eta(\%)$ & 21.10 & 69.60 & 82.10 \\
$q(\%)$ & 20.87 & 68.90 & 81.30 \\
\hline
\end{tabular}


Table 5

Calculated values of intramolecular energy transfer and back-transfer rates.

\begin{tabular}{lllll}
\hline Complexes & $\mathrm{W}_{\mathrm{ET}}\left(\mathrm{s}^{-1}\right)^{\mathrm{a}}$ & \multicolumn{3}{c}{$\mathrm{W}_{\mathrm{BT}}\left(\mathrm{s}^{-1}\right)^{\mathrm{b}}$} \\
\hline$\left[\mathrm{Eu}(\mathrm{Ibf})_{3}\left(\mathrm{H}_{2} \mathrm{O}\right)_{2}\right] \mathbf{1}$ & $\mathrm{S}_{1} \rightarrow{ }^{5} \mathrm{D}_{4}$ & 0.76 & ${ }^{5} \mathrm{D}_{4} \rightarrow \mathrm{S}_{1}$ & $2.16 \times 10^{-24}$ \\
& $\mathrm{~T}_{1} \rightarrow{ }^{5} \mathrm{D}_{1}$ & $9.45 \times 10^{7}$ & ${ }^{5} \mathrm{D}_{1} \rightarrow \mathrm{T}_{1}$ & $5.06 \times 10^{-7}$ \\
& $\mathrm{~T}_{1} \rightarrow{ }^{5} \mathrm{D}_{0}$ & $3.13 \times 10^{7}$ & ${ }^{5} \mathrm{D}_{0} \rightarrow \mathrm{T}_{1}$ & $4.10 \times 10^{-11}$ \\
& & & & \\
{$\left[E u_{2}(\text { Ibf })_{6}(\text { bpy })_{2}\right] \mathbf{4}$} & $\mathrm{S}_{1} \rightarrow{ }^{5} \mathrm{D}_{4}$ & 397 & ${ }^{5} \mathrm{D}_{4} \rightarrow \mathrm{S}_{1}$ & $5.32 \times 10^{-13}$ \\
& $\mathrm{~T}_{1} \rightarrow{ }^{5} \mathrm{D}_{1}$ & $3.50 \times 10^{8}$ & ${ }^{5} \mathrm{D}_{1} \rightarrow \mathrm{T}_{1}$ & $6.92 \times 10^{-2}$ \\
& $\mathrm{~T}_{1} \rightarrow{ }^{5} \mathrm{D}_{0}$ & $1.91 \times 10^{8}$ & ${ }^{5} \mathrm{D}_{0} \rightarrow \mathrm{T}_{1}$ & $9.23 \times 10^{-6}$ \\
& $\mathrm{~S}_{1} \rightarrow{ }^{5} \mathrm{D}_{4}$ & 8.54 & ${ }^{5} \mathrm{D}_{4} \rightarrow \mathrm{S}_{1}$ & $4.22 \times 10^{-21}$ \\
& $\mathrm{~T}_{1} \rightarrow{ }^{5} \mathrm{D}_{1}$ & $1.01 \times 10^{9}$ & ${ }^{5} \mathrm{D}_{1} \rightarrow \mathrm{T}_{1}$ & $1.28 \times 10^{2}$ \\
& $\mathrm{~T}_{1} \rightarrow{ }^{5} \mathrm{D}_{0}$ & $7.52 \times 10^{8}$ & ${ }^{5} \mathrm{D}_{0} \rightarrow \mathrm{T}_{1}$ & $2.33 \times 10^{-2}$ \\
\end{tabular}

a $* \mathrm{~W}_{\mathrm{ET}}=$ Transfer rate.

${ }^{\mathrm{b}} \mathrm{W}_{\mathrm{BT}}=$ Back-transfer rate.

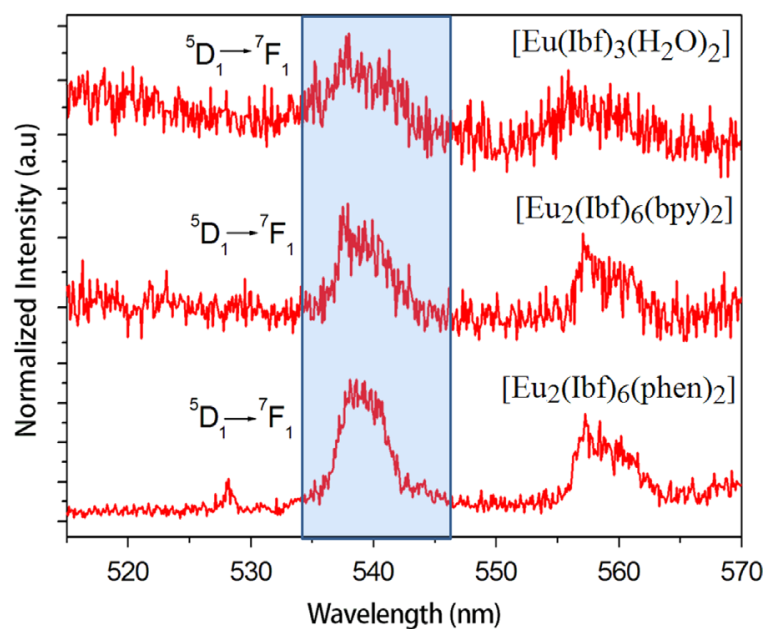

Fig. 9. ${ }^{5} \mathrm{D}_{1} \rightarrow{ }^{7} \mathrm{~F}_{1}$ transition of the Eu ${ }^{\mathrm{III}}$ complexes, at $77 \mathrm{~K}$.

ligands is displayed. Fig. 6a shows the phosphorescence spectra (steady-state and time-resolved) of $\left[\mathrm{Gd}(\mathrm{Ibf})_{3}\left(\mathrm{H}_{2} \mathrm{O}\right)_{2}\right]$ 2. In the steady-state spectrum can be observed two bands: the first band, centered at $335 \mathrm{~nm}$, attributed to the fluorescence $\left(\mathrm{S}_{1} \rightarrow \mathrm{S}_{0}\right)$, and a second band, centered at $452 \mathrm{~nm}$ assigned to the $\mathrm{T}_{1} \rightarrow \mathrm{S}_{0}\left(\pi, \pi^{*}\right)$ transition of phosphorescence emission. In the time-resolved spectra (delay of $1 \mathrm{~ms}$ ) the $\mathrm{T}_{1}$ state energy was estimated from the shortest wavelength on the base of the emission band, called of $0-0$ phonon transition, with the value of $385.1 \mathrm{~nm}$ $\left(25,974 \mathrm{~cm}^{-1}\right)$. In this system, the fluorescence band is very intense when compared to phosphorescence band and this fact can be explained taking into consideration the Reinhoudt's empirical rule [64]. According to this rule, the intersystem crossing process will be effective when the energy gap between singlet (S) and triplet (T) states of the ligands, $\Delta E=\left[S\left({ }^{1} \pi, \pi^{*}\right)-T\left({ }^{3} \pi, \pi^{*}\right)\right]$ is around $5000 \mathrm{~cm}^{-1}$. The singlet state energy was obtained from the diffuse reflectance spectrum of $\mathrm{Gd}^{\mathrm{III}}$ complex at $263 \mathrm{~nm}$ (38,022 $\left.\mathrm{cm}^{-1}\right)$, giving $\Delta E=12,048 \mathrm{~cm}^{-1}$. Thus, the intersystem crossing $\left(\mathrm{S}_{1} \rightarrow \mathrm{T}_{1}\right)$ not is effective, resulting in a higher fluorescence emission for the $\left[G d(I b f)_{3}\left(\mathrm{H}_{2} \mathrm{O}\right)_{2}\right] \mathbf{2}$. For the $\left[G d_{2}(\mathrm{Ibf})_{6}(\mathrm{bpy})_{2}\right] \mathbf{5}$ do not exist apparent differences between the two spectra (timeresolved and steady-state, in Fig. $6 \mathrm{~b}$ ) and the energy of triplet state $\left(\mathrm{T}_{1}\right)$ appears in $427.8 \mathrm{~nm}\left(23,419 \mathrm{~cm}^{-1}\right)$. Fig. $6 \mathrm{c}$ shows the steadystate phosphorescence spectrum of the $\left[G d_{2}(I b f)_{6}(\text { phen })_{2}\right] \mathbf{8}$ that displays two overlapped broad bands that are assigned to the fluorescence $\left(\mathrm{S}_{1} \rightarrow \mathrm{S}_{0}\right)$ (centered at $372.5 \mathrm{~nm}$ ) and phosphorescence due to the $T_{1} \rightarrow S_{0}\left(\pi, \pi^{*}\right)$ centered ligand transitions. The
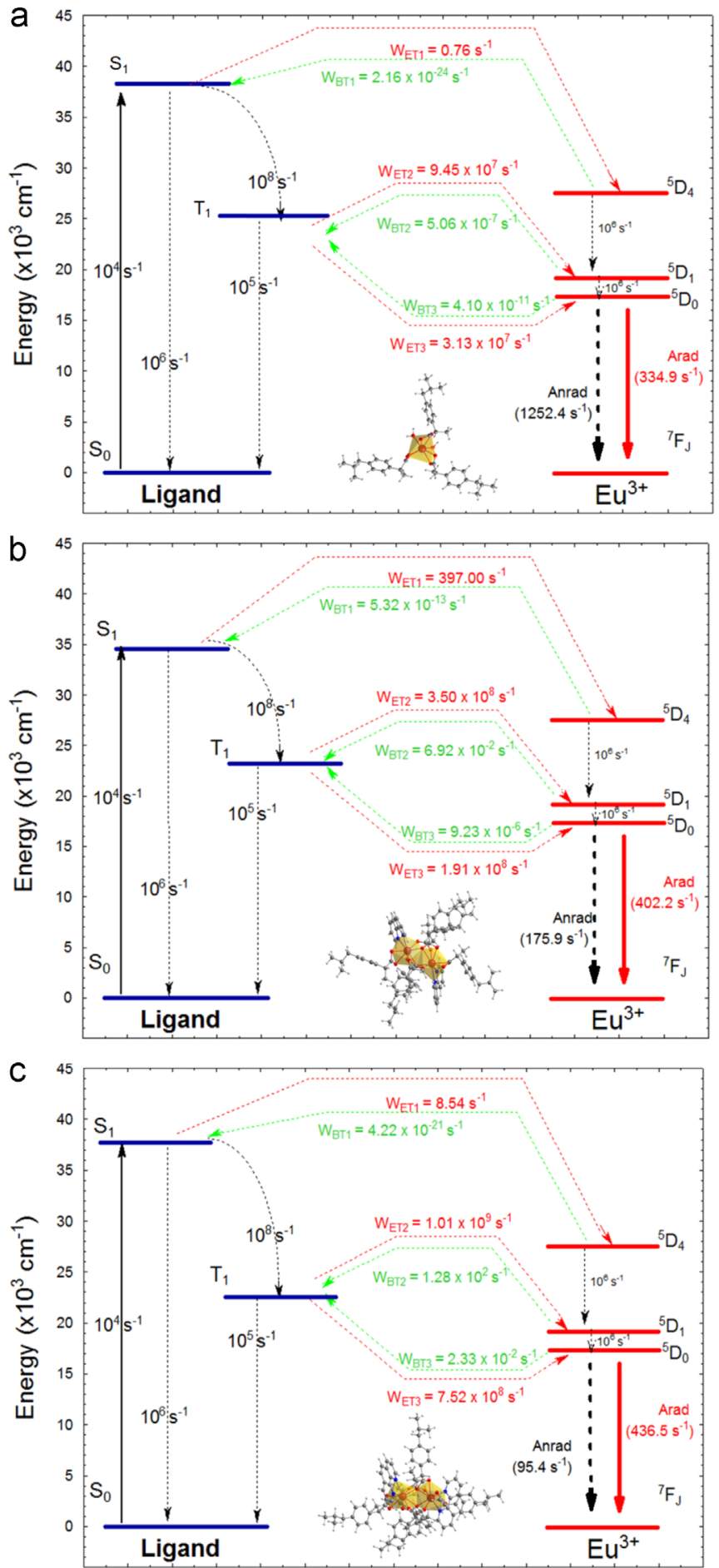

Fig. 10. Schematic energy diagram for the $\left[\mathrm{Eu}(\mathrm{Ibf})_{3}\left(\mathrm{H}_{2} \mathrm{O}\right)_{2}\right] \mathbf{1}(\mathrm{a}),\left[E u_{2}(\mathrm{Ibf})_{6}(b p y)_{2}\right] \mathbf{4}$ (b) and $\left.\left[\mathrm{Eu}_{2}(\mathrm{Ibf})_{6} \text { (phen }\right)_{2}\right] \mathbf{7}$ (c) Ibuprofen complexes showing the most probable channels for the intramolecular energy transfer process.

energy of the triplet states $\left(T_{1}\right)$ were determined from the $0-0$ phonon transition in the time-resolved (delay of $1 \mathrm{~ms}$ ) for the $\left[G d_{2}(\mathrm{Ibf})_{6}(\text { phen })_{2}\right] \mathbf{8}$ complex, and appears in $443.4 \mathrm{~nm}$ $\left(22,573 \mathrm{~cm}^{-1}\right)$. This behavior has been observed for several other lanthanide carboxylate complexes reported in the literature $[9,12]$. As can be observed, all these triplet states have energy higher than the main emitting states of $\mathrm{Eu}^{\mathrm{III}}\left({ }^{5} \mathrm{D}_{0}\right)$ and $\mathrm{Tb}^{\mathrm{III}}\left({ }^{5} \mathrm{D}_{4}\right)$, proving the possibility of intramolecular energy transfer in these complexes. 


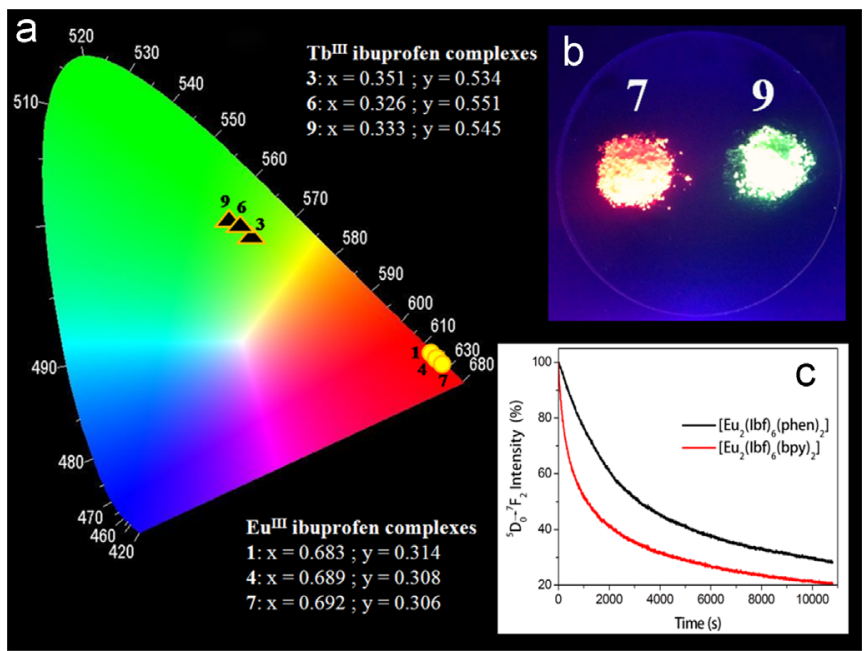

Fig. 11. (a) Chromaticity coordinates from emission spectra of the $\left[\mathrm{Ln}(\mathrm{Ibf})_{3}\left(\mathrm{H}_{2} \mathrm{O}\right)_{2}\right]$ $(\mathrm{Eu}=1, \mathrm{~Tb}=\mathbf{3}) ;\left[\operatorname{Ln}_{2}(\mathrm{Ibf})_{6}(\mathrm{bpy})_{2}\right](\mathrm{Eu}=\mathbf{4} ; \mathrm{Tb}=\mathbf{6})$ and $\left[\operatorname{Ln}_{2}(\mathrm{Ibf})_{6}(\text { phen })_{2}\right] \quad(\mathrm{Eu}=\mathbf{7}$ $\mathrm{Tb}=\mathbf{9}$ ) Ibuprofen complexes. (b) Photographs of complexes $\mathbf{7}$ and $\mathbf{9}$ (with a digital camera) displaying the intense photoluminescence in red and green regions, respectively, under UV irradiation.(c) Emission intensity of the $\mathbf{4}$ and $\mathbf{7}$ complexes versus the irradiation time $(\lambda=300 \mathrm{~nm})$. (For interpretation of the references to color in this figure legend, the reader is referred to the web version of this article.)

\subsubsection{Excitation and emission spectra of the $E u^{I I I}$ and $T b^{I I I}$ Ibuprofen complexes}

In order to explore the influence of the $\mathrm{N}, \mathrm{N}$-donors ligands on the luminescent properties of the $\mathrm{Eu}^{\mathrm{III}}$ and $\mathrm{Tb}^{\mathrm{III}}$ Ibuprofen complexes, the excitation (Figs. 7a and 8a) and the emission (Figs. 7b and 8 b) spectra are obtained in solid state at nitrogen temperature (77 K).

The excitation spectra of the Eu ${ }^{\text {III }}$ complexes are composed of broad band assigned to $S_{0} \rightarrow S_{1}\left(\pi, \pi^{*}\right)$ transition of the aromatic moiety and narrow bands (assigned to the $4 \mathrm{f}-4 \mathrm{f}$ transitions). These absorption bands are originated from the ${ }^{7} \mathrm{~F}_{0}$ ground state to the excited levels ${ }^{5} \mathrm{~L}_{\mathrm{J}}:{ }^{5} \mathrm{~L}_{9}(360 \mathrm{~nm}),{ }^{5} \mathrm{H}_{4}(379 \mathrm{~nm}),{ }^{5} \mathrm{~L}_{7}(385 \mathrm{~nm}),{ }^{5} \mathrm{~L}_{6}$ $(393 \mathrm{~nm}),{ }^{5} \mathrm{D}_{3}(415 \mathrm{~nm})$ and ${ }^{5} \mathrm{D}_{2}(464 \mathrm{~nm})$ excited states, and remain approximately invariable in each $\mathrm{Eu}^{\mathrm{III}}$ complex. For the $\left[E u_{2}(I b f)_{6}(\text { bpy })_{2}\right] \mathbf{4}$ and $\left[\mathrm{Eu}_{2}(\mathrm{Ibf})_{6}(\text { phen })_{2}\right] 7$ complexes, these transitions are less intense than those attributable to the ligands levels, which proves that luminescence sensitization is more efficient than the direct excitation in the Eu ${ }^{\mathrm{III}}$ ion absorption levels. Differently, in the $\left[\mathrm{Eu}(\mathrm{Ibf})_{3}\left(\mathrm{H}_{2} \mathrm{O}\right)_{2}\right] \mathbf{1}$ complex, the ${ }^{7} \mathrm{~F}_{0} \rightarrow{ }^{5} \mathrm{~L}_{6}$ transition (centered at $393 \mathrm{~nm}$ ) is more intense than that of the broad band attributable to the ligand level. This fact is an indicative that the direct excitation in the $\mathrm{Eu}^{\mathrm{III}}$ ion can result in high emission intensity. As shown in Fig. 6a, the excitation spectrum of the [Eu $\left.(\mathrm{Ibf})_{3}\left(\mathrm{H}_{2} \mathrm{O}\right)_{2}\right] 1$ complex show a broad band, and the edge of these broad band seems to go toward lower energies (at approximately $354 \mathrm{~nm}$ ) showing the contribution of possible energy LMTC states, as provided in the DR spectroscopy.

The emission spectra of the europium complexes provide a lot of information about the point symmetry around the $\mathrm{Eu}^{\mathrm{III}}$ ion and also about the degree of covalence between Eu-L bonds [65,66]. Fig. 7b shows the ${ }^{5} \mathrm{D}_{0} \rightarrow{ }^{7} \mathrm{~F}_{J}(J=0,1,2,3$ and 4$)$ transitions in the emission

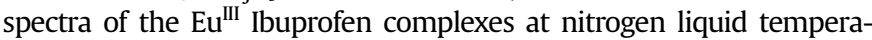
ture. In each case, the excitation is at the maximum on the left side show in Fig. 7a, corresponding to levels centered into the ligands. All peaks in the emission spectra originate from the ${ }^{5} \mathrm{D}_{0}$ level. In this context, for all of them, the ${ }^{5} \mathrm{D}_{0} \rightarrow{ }^{7} \mathrm{~F}_{2}$ transition is more intense than that ${ }^{5} D_{0} \rightarrow{ }^{7} F_{1}$ transition, indicating that the forced electric dipole and the dynamic coupling mechanisms are predominant in relation to magnetic dipole one, because the Eu ${ }^{\text {III }}$ ions is located in a low symmetry site. It is important to point out that the ${ }^{5} \mathrm{D}_{0} \rightarrow{ }^{7} \mathrm{~F}_{J}(J=0,1,2$,
3 and 4) transitions for the $\left[\mathrm{Eu}(\mathrm{Ibf})_{3}\left(\mathrm{H}_{2} \mathrm{O}\right)_{2}\right] \mathbf{1}$ complex are broader when compared to other complexes, proving their low crystallinity degree, as evidenced by the PXRD results. The presence of the ${ }^{5} \mathrm{D}_{0} \rightarrow{ }^{7} \mathrm{~F}_{0}$ transition, which appears only in low symmetries as $C_{n v}, C_{n}$ or $C_{s}$, indicates that all the complexes present a low symmetry coordination geometry, as the selection rules for the electric dipole transition provides. Such transitions consist of only one peak, which gives a strong indication that the $\mathrm{Eu}^{\mathrm{III}}$ ions experience the same crystal-field strength and occupy sites of same symmetry in the complexes. To confirm these results, a magnification of the emission spectrum in ${ }^{5} \mathrm{D}_{0} \rightarrow{ }^{7} \mathrm{~F}_{0}$ region was obtained at $77 \mathrm{~K}$ (Fig. S5 in Supplementary material), and no splittings of this bands were observed. In order to promote a comparison between $\left[\mathrm{Eu}(\mathrm{Ibf})_{3}\left(\mathrm{H}_{2} \mathrm{O}\right)_{2}\right] \mathbf{1},\left[\mathrm{Eu}_{2}(\mathrm{Ibf})_{6}(\mathrm{bpy})_{2}\right] \mathbf{4}$ and $\left[\mathrm{Eu}_{2}(\mathrm{Ibf})_{6}(\text { phen })_{2}\right] 7$ complexes, the ${ }^{5} \mathrm{D}_{0} \rightarrow{ }^{7} \mathrm{~F}_{0}$ transition centroid energy was determined and the values are: $581.8 \mathrm{~nm}\left(\sim 17,188 \mathrm{~cm}^{-1}\right)$ for $\left[\mathrm{Eu}(\mathrm{Ibf})_{3}\left(\mathrm{H}_{2} \mathrm{O}\right)_{2}\right] \mathbf{1}, 581.5 \mathrm{~nm}\left(17,196 \mathrm{~cm}^{-1}\right)$ for $\left[\mathrm{Eu}_{2}(\mathrm{Ibf})_{6}(\mathrm{bpy})_{2}\right] \mathbf{4}$, and $582.8 \mathrm{~nm}\left(17,158 \mathrm{~cm}^{-1}\right)$ for $\left[\mathrm{Eu}_{2}(\mathrm{Ibf})_{6}(\text { phen })_{2}\right] \mathbf{7}$ (Fig. S5 in Supplementary material). These results indicate that the complexes covalence depends on the ancillary ligand nature. For example, the covalence in the Eu-L is higher for 1,10 phenanthroline (phen) than for 2,2'-bipyridine (bpy), corroborating the higher value of $\Omega_{2}$ for $\left[\mathrm{Eu}_{2}(\mathrm{Ibf})_{6}(\mathrm{phen})_{2}\right] \mathbf{7}$ when compared with the $\left[\mathrm{Eu}_{2}(\mathrm{Ibf})_{6}(\mathrm{bpy})_{2}\right] \mathbf{4}$ complex (Table 3). Similar results were reported for $\left[E u\left(E t_{2} N C S_{2}\right)_{3} b p y\right]$ and [Eu $\left(\mathrm{Et}_{2} \mathrm{NCS}_{2}\right)_{3}$ phen] complexes [67] and for several other complexes in chloroformic solutions [68]. As expected, the ${ }^{5} \mathrm{D}_{0} \rightarrow{ }^{7} \mathrm{~F}_{0}$ transition of the $\left[\mathrm{Eu}(\mathrm{Ibf})_{3}\left(\mathrm{H}_{2} \mathrm{O}\right)_{2}\right] \mathbf{1}$ compound is broader than that these same transitions for the $\left[E u_{2}(I b f)_{6}(b p y)_{2}\right] \mathbf{4}$ and $\left[E u_{2}(I b f)_{6}(\text { phen })_{2}\right] \mathbf{7}$ complexes. The number of splittings in the Eu ${ }^{\text {III }}$ emission spectra may be correlated with the point symmetry. Thus, in a first approximation, the emission spectrum (at $77 \mathrm{~K}$ ) of $\left[\mathrm{Eu}_{2}(\mathrm{Ibf})_{6}(\text { phen })_{2}\right] \mathbf{7}$ complex show more splittings for each transition ${ }^{5} \mathrm{D}_{0} \rightarrow{ }^{7} \mathrm{~F}_{\mathrm{J}}$ when compared with the [Eu $\left.(\mathrm{Ibf})_{3}\left(\mathrm{H}_{2} \mathrm{O}\right)_{2}\right] \mathbf{1}$ and $\left[\mathrm{Eu}_{2}(\mathrm{Ibf})_{6}(\mathrm{bpy})_{2}\right] \mathbf{4}$ complexes. This fact, suggests that the chemical environment around the $\mathrm{Eu}^{\mathrm{III}}$ ion in the $\left[\mathrm{Eu}_{2}(\mathrm{Ibf})_{6}(\text { phen })_{2}\right] \mathbf{7}$ is less symmetric than that of the $\left[\mathrm{Eu}(\mathrm{Ibf})_{3}\left(\mathrm{H}_{2} \mathrm{O}\right)_{2}\right] \mathbf{1}$ and $\left[\mathrm{Eu}_{2}(\mathrm{Ibf})_{6}(\mathrm{bpy})_{2}\right] \mathbf{4}$ complexes. Fig. 8 a shows the excitation spectra of $\mathrm{Tb}^{\mathrm{III}}$ complexes recorded at $77 \mathrm{~K}$ in the $250-500$ range by monitoring the emission ${ }^{5} \mathrm{D}_{4} \rightarrow{ }^{7} \mathrm{~F}_{5}$ transition at $546 \mathrm{~nm}$.

It can be clearly seen that excitation spectra consists of a strong and broad band assigned to $S_{0} \rightarrow S_{1}\left(\pi, \pi^{*}\right)$ transition of the aromatic moiety. The presence of the energy LMTC states is more unlikely for the $\mathrm{Tb}^{\mathrm{III}}$ complexes because of the lower $\mathrm{Tb}^{\mathrm{III}} \rightarrow \mathrm{Tb}^{\mathrm{II}}$ potential of reduction. This fact can be evidenced by the narrowing of the excitation bands edges when compared with the $\mathrm{Eu}^{\text {III }}$ compounds. In addition, several narrow bands are also observed and are assigned to $4 \mathrm{f}^{8}$-intraconfigurational transitions from the ground state ${ }^{7} \mathrm{~F}_{6}$ to the following excited states of terbium ion: ${ }^{5} \mathrm{~L}_{6}$ $(340 \mathrm{~nm}),{ }^{5} \mathrm{~L}_{9}(349 \mathrm{~nm}),{ }^{5} \mathrm{G}_{5}(357 \mathrm{~nm}),{ }^{5} \mathrm{~L}_{10}(366 \mathrm{~nm}),{ }^{5} \mathrm{D}_{3}(376 \mathrm{~nm})$ and ${ }^{5} \mathrm{D}_{4}(484 \mathrm{~nm})$. These transitions are less intense than that of the broad bands attributable to the ligand levels, which proves that luminescence sensitization via ligand excitation is more efficient than the direct excitation of $\mathrm{Tb}^{\mathrm{III}}$ ion absorption levels. However, the $4 \mathrm{f}-4 \mathrm{f}$ absorptions bands in these complexes are much less intense than that of the analogous $\mathrm{Eu}^{\mathrm{III}}$ complexes, indicating more effective direct excitation of lanthanide centers in the $\mathrm{Eu}^{\mathrm{III}}$ complexes. The emission spectra of the $\mathrm{Tb}^{\mathrm{III}}$ complexes (Fig. 8b) are composed of the typical ${ }^{5} \mathrm{D}_{4} \rightarrow{ }^{7} \mathrm{~F}_{\mathrm{J}}$ emissions, with $J=6$, 5, 4, 3, 2 and 1. Similarly to the $\left[\mathrm{Eu}(\mathrm{Ibf})_{3}\left(\mathrm{H}_{2} \mathrm{O}\right)_{2}\right] \mathbf{1}$ complex, the ${ }^{5} \mathrm{D}_{4} \rightarrow{ }^{7} \mathrm{~F}_{\mathrm{J}}$ transitions for the $\left[\mathrm{Tb}(\mathrm{Ibf})_{3}\left(\mathrm{H}_{2} \mathrm{O}\right)_{2}\right] \mathbf{3}$ are broader, proving their low crystallinity degree, as evidenced by the PXRD results. Another feature in photoluminescence data of the $\mathrm{Eu}^{\mathrm{III}}$ and $\mathrm{Tb}^{\mathrm{III}}$ Ibuprofen complexes is that the emission spectra do not exhibit the broad phosphorescence band of the ligands that is observed in the $\mathrm{Gd}^{\mathrm{III}}$ complexes (see Fig. 6a-c), indicating energy transfer ligand-Eu ${ }^{\mathrm{III}} / \mathrm{Tb}^{\mathrm{III}}$ ion. 


\subsubsection{Luminescence decay profiles}

The emission lifetimes $(\tau)$ for the $\mathrm{Eu}^{\mathrm{III}}$ and $\mathrm{Tb}^{\mathrm{III}}$ Ibuprofen complexes were obtained in the solid state, at $300 \mathrm{~K}$, under excitation at singlet states, with emission monitored at ${ }^{5} \mathrm{D}_{0} \rightarrow{ }^{7} \mathrm{~F}_{2}$ and ${ }^{5} \mathrm{D}_{4} \rightarrow{ }^{7} \mathrm{~F}_{5}$ transitions for $\mathrm{Eu}^{\mathrm{III}}$ and $\mathrm{Tb}^{\mathrm{III}}$, respectively (Fig. $\mathrm{S} 6$ in Supplementary material). The relatively shorter lifetimes observed for the [ $\mathrm{Ln}$ $\left.(\mathrm{Ibf})_{3}\left(\mathrm{H}_{2} \mathrm{O}\right)_{2}\right](\mathbf{1}-\mathbf{3})\left(\mathrm{Ln}=\mathrm{Eu}^{\mathrm{III}}\right.$ and $\left.\mathrm{Tb}^{\mathrm{III}}\right)$ complexes is due the presence of high frequencies oscillators in the coordinated water molecules, which activate the non-radiative decay pathways. In the case of the $\mathrm{Eu}^{\mathrm{III}}$ ion, the energy gap between the first excited state $\left({ }^{5} \mathrm{D}_{0}\right)$ and the ground state level $\left({ }^{7} F_{0}\right)$ is $\sim 12,000 \mathrm{~cm}^{-1}$. Thus, in the presence of coordination water molecules, the coupling of the $\mathrm{Eu}^{\mathrm{III}}$ states and the third vibrational overtone of the $\mathrm{O}-\mathrm{H}$ oscillators $(\sim 3300$ to $3500 \mathrm{~cm}^{-1}$ ) will be effective, which is responsible by the quenching of luminescence in the $\left[\mathrm{Ln}(\mathrm{Ibf})_{3}\left(\mathrm{H}_{2} \mathrm{O}\right)_{2}\right](\mathrm{Ln}=\mathrm{Eu} 1$ and Tb 3) complexes. However, these non-radiative decay pathways are limited in the $\left[\operatorname{Ln}_{2}(\mathrm{Ibf})_{6}(\mathrm{bpy})_{2}\right]$ (Eu 4 and $\left.\mathrm{Tb} \mathbf{6}\right)$ and $\left[\mathrm{Ln}_{2}(\mathrm{Ibf})_{6}(\text { phen })_{2}\right]$ (Eu 7 and $\mathrm{Tb}$ 9) complexes, which thereby exhibit longer lifetime values. Each of the decay curves (Fig. S9 in Supplementary material) follows monoexponential decay law, and the equation intensity $=A_{1} \cdot \exp (-x /$ $\left.t_{1}\right)+y_{0}$ was used for fitting the fluorescence decay curves, indicating only one type of emitter sites in all the $\mathrm{Eu}^{\mathrm{III}}$ and $\mathrm{Tb}^{\mathrm{III}}$ Ibuprofen complexes. It is important to point out that, this fact is in perfect agreement with the structural characteristics of the synthesized compounds: in the mononuclear compounds $\left[\mathrm{Ln}(\mathrm{Ibf})_{3}\left(\mathrm{H}_{2} \mathrm{O}\right)_{2}\right](\mathbf{1}-\mathbf{3})$, all the $\mathrm{Ln}^{\mathrm{III}}$ ions are in the same type of symmetry. In the binuclear compounds $\left[\operatorname{Ln}_{2}(I b f)_{6}(b p y)_{2}\right]$ (4-6) and $\left[\operatorname{Ln}_{2}(I b f)_{6}(\text { phen })_{2}\right]$ (7-9) the two $\mathrm{Ln}^{\mathrm{III}}$ centers are both equivalent in the coordination environment, as observed in several binuclear compounds of this type [9,12]. Additionally, in the same system, the $\tau$ values of $\mathrm{Tb}^{\mathrm{III}}$ ion are higher than those of $\mathrm{Eu}^{\mathrm{III}}$ ion, due to the larger energy gap between the excited states of terbium ion $\left(\sim 14,800 \mathrm{~cm}^{-1}\right)$ compared with the europium gap $\left(\sim 12,300 \mathrm{~cm}^{-1}\right)$.

\subsubsection{Energy transfer mechanism in the $E u^{I I I}$ and $\mathrm{Tb}^{I I I}$ Ibuprofen complexes}

Measurements of the photoluminescence of lanthanide complexes originating from intramolecular energy transfer from the ligand to the $\mathrm{Ln}^{\mathrm{III}}$ ion have been employed as a fundamental technique for determination of several substances of biological importance, as the non-steroidal anti-inflammatory drug (NSAID) Ibuprofen $[18,19]$. In this context, the determination of the lowest ligand triplet state $\left(T_{1}\right)$ energy is very important to investigate the energy transfer mechanism in the lanthanide coordination compounds. These $T_{1}$ energy states were estimated from the shortest wavelength on phosphorescence spectra ( $0-0$ phonon transition) of the related $\mathrm{Gd}^{\mathrm{III}}$ compounds. Taking into consideration the $\mathrm{T}_{1}$ energy states, one of the factors that governs the luminescence efficiency of the lanthanide complexes is the energy-level match between the ligand triplet states and $\mathrm{Ln}^{\mathrm{III}}$ ion ${ }^{5} \mathrm{D}_{\mathrm{J}}$ state. Thus, the back energy-transfer process is one of the major mechanism of luminescence quenching in $\mathrm{Tb}^{\mathrm{III}}$ complexes. Thus, Latva's empirical rule states [69] show that an efficient ligand-to-metal energy transfer process for $\mathrm{Ln}^{\text {III }}$ needs $\Delta E\left({ }^{3} \pi \pi^{*}-{ }^{5} \mathrm{D}_{\mathrm{J}}\right)>2000 \mathrm{~cm}^{-1}$ for $\mathrm{Tb}^{\text {III }}$. In all $\mathrm{Tb}^{\text {III }}$ complexes, the energy gap $\Delta E\left({ }^{3} \pi \pi^{*}-{ }^{5} \mathrm{D}_{4}\right)$ is bigger $\left(5608 \mathrm{~cm}^{-1}\right.$ for $3 ; 2998 \mathrm{~cm}^{-1}$ for 6 and $2258 \mathrm{~cm}^{-1}$ for 9) than $2000 \mathrm{~cm}^{-1}$, justifying the effective ligand-to-metal energy transfer process in these $\mathrm{Tb}^{\mathrm{III}}$ Ibuprofen complexes. The smallest energy gap in $\left[\mathrm{Tb}_{2}(\mathrm{Ibf})_{6}(\text { phen })_{2}\right] \mathbf{9}$ compound, studied here, can be explained checking triplet states energy: $22,624 \mathrm{~cm}^{-1}$ in $\left[G d_{2}(\mathrm{Ibf})_{6}(\text { phen })_{2}\right] \mathbf{8}$, $23,364 \mathrm{~cm}^{-1}$ in $\left[G d_{2}(\mathrm{Ibf})_{6}(\text { bpy })_{2}\right] \mathbf{5}$ and $25,974 \mathrm{~cm}^{-1}$ in $[G d$ $\left.(\mathrm{Ibf})_{3}\left(\mathrm{H}_{2} \mathrm{O}\right)_{2}\right]$ 3. The lowest ligands $\mathrm{T}_{1}$ energy levels have energy higher than the main emitting states of $\mathrm{Eu}^{\mathrm{III}}\left({ }^{5} \mathrm{D}_{0}\right)$ and $\mathrm{Tb}^{\mathrm{III}}\left({ }^{5} \mathrm{D}_{4}\right)$, proving the possibility of intramolecular energy transfer in these complexes. Therefore, the photoluminescence mechanism in the $\mathrm{Eu}^{\mathrm{III}}$ and $\mathrm{Tb}^{\mathrm{III}}$ Ibuprofen complexes is proposed to be a ligand sensitized luminescence process, the antenna effect. The experimental Judd-Ofelt intensity parameters $\left(\Omega_{2}\right.$ and $\left.\Omega_{4}\right)$, radiative and nonradiative rates of spontaneous emission ( $A_{\text {rad }}$ and $A_{\text {nrad, }}$, respectively) and quantum efficiency $(\eta)$ for the $\mathrm{Eu}^{\mathrm{III}}$ ion in the complexes were determined from the emission spectra (Table 3 ), providing valuable information about the intramolecular energy transfer process in the $\left[\mathrm{Eu}(\mathrm{Ibf})_{3}\left(\mathrm{H}_{2} \mathrm{O}\right)_{2}\right] \mathbf{1},\left[\mathrm{Eu}_{2}(\mathrm{Ibf})_{6}(b p y)_{2}\right] \mathbf{4}$ and $\left[\mathrm{Eu}_{2}(\mathrm{Ibf})_{6}(\text { phen })_{2}\right] 7$ complexes.

A high value of $A_{\text {nrad }}\left(1226.00 \mathrm{~cm}^{-1}\right)$ for the $\left[\mathrm{Eu}(\mathrm{Ibf})_{3}\left(\mathrm{H}_{2} \mathrm{O}\right)_{2}\right] \mathbf{1}$ is due to the effect of the vibronic coupling of the higher energy $\mathrm{O}-$ $\mathrm{H}$ oscillator from coordinated water molecules and ${ }^{5} \mathrm{D}_{0}$ emitting level, causing a nonradiative dissipation of energy. In addition, the presence of methyl groups in the Ibuprofen ligands may also promote the quenching of luminescence by $\mathrm{C}-\mathrm{H}$ oscillators high frequencies vibrations. These experimental data reveals that the substitution of the water molecule in $\left[\mathrm{Eu}(\mathrm{Ibf})_{3}\left(\mathrm{H}_{2} \mathrm{O}\right)_{2}\right] \mathbf{1}$ by the N,Ndonors ligands (bpy and phen) leads the formation of the binuclear compounds $\left[E u_{2}(I b f)_{6}(b p y)_{2}\right] \mathbf{4}$ and $\left[E u_{2}(I b f)_{6}(\text { phen })_{2}\right] \mathbf{7}$, resulting in an approximately 3 -fold increase in the quantum efficiency for the complex $\mathbf{4}$ and 4 -fold for the complex $\mathbf{7}$ when compared with the complex $\mathbf{1}$ (Table 3 ). The higher intensity of emission is probably due to the fact that the triplet states (of the ligands) present the best resonance with the $\mathrm{Eu}^{\mathrm{III}}$ ions emission states in the bimetallic compounds. Considering now these two binuclear compounds, the stronger luminescence observed for $\left[\mathrm{Eu}_{2}(\mathrm{Ibf})_{6}(\text { phen })_{2}\right] \mathbf{7}$ can be associated to a greater structural rigidity of phen ligand, allowing a better energy transfer ligandsto-metal. The rigid structure restricts the thermal vibration of the ligand and reduces the energy loss by radiationless decay, as can be seen by the lower $A_{\text {nrad }}$ rate. Yang et al. [70] reported similar fact, comparing a more intense emission for $\left[\mathrm{Eu}(\mathrm{tta})_{3}(\right.$ phen $\left.)\right]$ than for $\left[E u(t t a)_{3}(b p y)\right]$. Table 4 summarizes the theoretical values for the intensity parameters $\left(\Omega_{2}, \Omega_{4}\right.$ and $\left.\Omega_{6}\right)$, radiative and nonradiative rates of spontaneous emission $\left(A_{\text {rad }}\right.$ and $A_{\text {nrad, }}$ respectively), quantum efficiency $(\eta)$ and quantum yield $(q)$ for the $[E u$ $\left.(\mathrm{Ibf})_{3}\left(\mathrm{H}_{2} \mathrm{O}\right)_{2}\right] \mathbf{1},\left[\mathrm{Eu}_{2}(\mathrm{Ibf})_{6}(\mathrm{bpy})_{2}\right] \mathbf{4}$ and $\left[\mathrm{Eu}_{2}(\mathrm{Ibf})_{6}(\text { phen })_{2}\right] \mathbf{7}$ complexes studied in this paper.

According to the photophysical data presented in the Tables 3 and 4, the analysis of the intensity parameters $\Omega_{\lambda}(\lambda=2$ and 4 ) and decay rates ( $A_{\text {rad }}$ and $A_{\text {nrad }}$ ) leads to the conclusion that these results reflect a good agreement between the theoretical and experimental data. We retake here, the data that support the presence of two coordination water molecules for the mononuclear complex $\left[\mathrm{Eu}(\mathrm{Ibf})_{3}\left(\mathrm{H}_{2} \mathrm{O}\right)_{2}\right] \mathbf{1}$ instead of complex [Eu $\left.(\mathrm{Ibf})_{3}\right] .1 .5 \mathrm{H}_{2} \mathrm{O}$ [13], where the authors suggest the presence of lattice water molecules. We compared some luminescent properties such as the Judd-Ofelt intensity parameters $\Omega_{\lambda}(\lambda=2$ and 4$)$ and the decay rates $\left(A_{\text {rad }}\right.$ and $\left.A_{\text {nrad }}\right)$ calculated from the $\left[\mathrm{Eu}(\mathrm{Ibf})_{3}\left(\mathrm{H}_{2} \mathrm{O}\right)_{2}\right]$ 1 and $\left[\mathrm{Eu}(\mathrm{Ibf})_{3}\right] \cdot 1.5 \mathrm{H}_{2} \mathrm{O}$ molecular structures by the RM1 model. This analysis revealed that the suggested [Eu(Ibf) $\left.)_{3}\left(\mathrm{H}_{2} \mathrm{O}\right)_{2}\right] \mathbf{1} \mathrm{com}-$ plex provides a better match between the empirically and theoretically Judd-Ofelt parameters and decay rates values (Table S4, in Supplementary material). Thus, the agreement between the experimental and calculated data (RM1 model) make us believe that the $\left[\mathrm{Eu}(\mathrm{Ibf})_{3}\left(\mathrm{H}_{2} \mathrm{O}\right)_{2}\right] \mathbf{1}$ compound studied here, is not the same reported by Gálico et al. [13]. Another important quantity to enable the energy transfer rates calculations is the energy position of the singlet and triplet excited states. The corresponding calculated values of excited state energies are: singlet $\left(\mathrm{S}_{1}\right)=$ $38,890.20 \mathrm{~cm}^{-1}$, triplet $\left(\mathrm{T}_{1}\right)=25,879.10 \mathrm{~cm}^{-1}$ for $\left[\mathrm{Eu}(\mathrm{Ibf})_{3}\left(\mathrm{H}_{2} \mathrm{O}\right)_{2}\right] \mathbf{1}$, singlet $\left(\mathrm{S}_{1}\right)=34,726.60 \mathrm{~cm}^{-1}$, triplet $\left(\mathrm{T}_{1}\right)=23,686.10 \mathrm{~cm}^{-1}$ for $\left[\mathrm{Eu}_{2}(\mathrm{Ibf})_{6}(\mathrm{bpy})_{2}\right] \mathbf{4}$ and singlet $\left(\mathrm{S}_{1}\right)=37,815.40 \mathrm{~cm}^{-1}$, triplet $\left(\mathrm{T}_{1}\right)=$ $22,338.50 \mathrm{~cm}^{-1}$ for $\left[E u_{2}(I b f)_{6}(\text { phen })_{2}\right]$ 7, with these results reflecting excellent agreement between the theoretical and experimental data. Table 5 presents the intramolecular energy 
transfer $\left(\mathrm{W}_{\mathrm{ET}}\right)$ and back-transfer $\left(\mathrm{W}_{\mathrm{BT}}\right)$ rates for the $[\mathrm{Eu}$ $\left.(\mathrm{Ibf})_{3}\left(\mathrm{H}_{2} \mathrm{O}\right)_{2}\right] \mathbf{1},\left[\mathrm{Eu}_{2}(\mathrm{Ibf})_{6}(\mathrm{bpy})_{2}\right] \mathbf{4}$ and $\left[\mathrm{Eu}_{2}(\mathrm{Ibf})_{6}(\text { phen })_{2}\right] \mathbf{7}$ systems.

As we can observe, the triplet $\rightarrow{ }^{5} \mathrm{D}_{1}$ and triplet $\rightarrow{ }^{5} \mathrm{D}_{0}$ are the main energy transfer channels, considering $\mathrm{W}_{\mathrm{ET}}$ only. An additional elucidation should be done at this point: in the case of $\mathrm{Tb}^{\mathrm{III}}$ complexes only the ${ }^{5} \mathrm{D}_{4}$ level is suitable for energy transfer, once that the other components of the multiplet ${ }^{5} \mathrm{D}_{\mathrm{J}}$ are lying at substantially higher energies. On the other hand, in the Eu ${ }^{\text {III }}$ complexes, the components of the ${ }^{5} \mathrm{D}_{\mathrm{J}}$ multiplet are relatively close in energy, and therefore the energy transfer can occur on either ${ }^{5} D_{1}$ or ${ }^{5} \mathrm{D}_{0}$. To confirm these results, an emission spectrum at ${ }^{5} \mathrm{D}_{1} \rightarrow{ }^{7} \mathrm{~F}_{1}$ region was obtained at $77 \mathrm{~K}$ (Fig. 9), revealing the presence of this transition in the 1,4 and 7 , suggesting the ${ }^{5} D_{1} \rightarrow{ }^{7} F_{1}$ path for the $\mathrm{Eu}^{\mathrm{III}}$ complexes. The presence of the ${ }^{5} \mathrm{D}_{1} \rightarrow{ }^{7} \mathrm{~F}_{1}$ transition in these

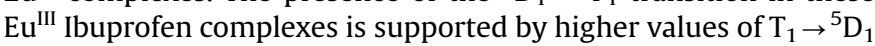
energy transfer rates in all Eu ${ }^{\text {III }}$ complexes, as showed in Table 5. Comparing these three $\mathrm{Eu}^{\mathrm{III}}$ Ibuprofen complexes in study, the highest value of $\mathrm{W}_{\mathrm{ET}}\left(\mathrm{T}_{1} \rightarrow{ }^{5} \mathrm{D}_{1}\right)$ is found for the $\left[\mathrm{Eu}_{2}(\mathrm{Ibf})_{6}(\text { phen })_{2}\right] 7$ $\left(1.01 \times 10^{-9} \mathrm{~s}^{-1}\right)$ because the best ressonance condition between $\mathrm{T}_{1}$ and ${ }^{5} \mathrm{D}_{1}$, which in turn also favors the high ${ }^{5} \mathrm{D}_{1} \rightarrow \mathrm{T}_{1}$ backtransfer rate. Additionally, the transitions from ${ }^{5} \mathrm{D}_{1}$ excited state to ${ }^{7} F_{J}$ multiplet exhibit extremely low intensity because the ${ }^{5} D_{0}$ and ${ }^{5} \mathrm{D}_{1}$ levels have small energy gap, and so, the transfer of energy ${ }^{5} \mathrm{D}_{1} \rightarrow{ }^{5} \mathrm{D}_{0}$ is preferred in relation to electronic transitions ${ }^{5} \mathrm{D}_{1} \rightarrow{ }^{7} \mathrm{~F}_{J}$ $(J=0-6)$.

The back-transfer rates shows high values in case of ${ }^{5} \mathrm{D}_{1} \rightarrow \mathrm{T}_{1}$ and ${ }^{5} D_{0} \rightarrow T_{1}$ compared with the values of ${ }^{5} D_{4} \rightarrow S_{1}$, and this suggest the higher resonance between triplet and ${ }^{5} \mathrm{D}_{1}$ states. These results agree with the experimentally observed with the position of triplet states. The proposed energy transfer diagram for the [ $\mathrm{Eu}$ $\left.(\mathrm{Ibf})_{3}\left(\mathrm{H}_{2} \mathrm{O}\right)_{2}\right] \mathbf{1}$ is show in Fig. 10a, while such diagrams for the $\left[\mathrm{Eu}_{2}(\mathrm{Ibf})_{6}(\mathrm{bpy})_{2}\right] \mathbf{4}$ and $\left[E u_{2}(\mathrm{Ibf})_{6}(\text { phen })_{2}\right] \mathbf{7}$ complexes are exhibited in the Fig. 10b and c, respectively. Full lines concern the radiative transitions, whereas the dashed lines concern those associated with non-radiative paths. The curved lines are related to the ligand $\rightarrow$ lanthanide energy transfer or back-transfer. The calculation of the distance difference between donor and acceptor states involved in the process of energy transfer $\left(R_{L}\right)$, depends on the molecular orbital coefficients of the corresponding atoms that contributes to the ligands states (singlet or triplet), and the distance from the that atom to the lanthanide ion. The $R_{L}$ values obtained are: $6.92 \AA$ for $\left[\mathrm{Eu}(\mathrm{Ibf})_{3}\left(\mathrm{H}_{2} \mathrm{O}\right)_{2}\right] \mathbf{1}, 6.34 \AA$ for $\left[E u_{2}(I b f)_{6}(b p y)_{2}\right] 4$ and $6.32 \AA$ for $\left[E u_{2}(I b f)_{6}(\text { phen })_{2}\right]$ 7. As commented previously, detailed studies on the photoluminescence properties for compounds of $\mathrm{Eu}^{\mathrm{III}}$ with Ibuprofen ligand are inexistent in the literature, making impossible a comparison with other similar compounds. However, the lowest $R_{L}$ value calculated for $\left[\mathrm{Eu}_{2}(\mathrm{Ibf})_{6}(\mathrm{phen})_{2}\right] \mathbf{7}$ when compared to $\left[\mathrm{Eu}_{2}(\mathrm{Ibf})_{6}(\mathrm{bpy})_{2}\right] \mathbf{4}$, favors a good ressonance condition between the organic ligand and the central ion in 7, in agreement with the highest value of quantum efficiency for this compound.

The Eu ${ }^{\text {III }}$ Ibuprofen complexes present similar $(\mathrm{x}, \mathrm{y})$ color coordinates in the red region of the CIE chromaticity diagram (Commission Internationale l'Eclairage) from intraconfigurational $4 \mathrm{f}-4 \mathrm{f}$ transitions (Fig. 11a), with the compound $\left[E u_{2}(I b f)_{6}(\text { phen })_{2}\right] \mathbf{7}$ producing an intense monochromatic emission (Fig. 11b). The $\left[\mathrm{Tb}(\mathrm{Ibf})_{3}\left(\mathrm{H}_{2} \mathrm{O}\right)_{2}\right] 3$ complex displays the green-yellow emission color when compared to $\left[\mathrm{Tb}_{2}(\mathrm{Ibf})_{6}(\mathrm{bpy})_{2}\right] \mathbf{6}$ and $\left[\mathrm{Tb}_{2}(\mathrm{Ibf})_{6}(\text { phen })_{2}\right] \mathbf{9}$ complexes, that produce green color. Therefore, these complexes act as light conversion molecular devices (LCMDs) producing intense monochromatic emission colors, fact very important in biological assays for molecular recognition of Ibuprofen $[18,19]$. Owing to the excellent luminescent properties of $\left[E u_{2}(I b f)_{6}(b p y)_{2}\right] \mathbf{4}$ and $\left[E u_{2}(I b f)_{6}(\text { phen })_{2}\right]$ 7, a brief photostability study was performed, with the complexes being subjected to a radiation of $300 \mathrm{~nm}$ (UV-A) for a period of $3 \mathrm{~h}(11,000 \mathrm{~s})$, showing that both complexes were degraded when compared with those not irradiated. However, the $\left[\mathrm{Eu}_{2}(\mathrm{Ibf})_{6}(\mathrm{bpy})_{2}\right] \mathbf{4}$ complex presented a stronger reduction of the emission intensity (Fig. 11c). In general, incorporation of these complexes into an inorganic hybrid matrix significantly improves its thermal photostability. Research along this line for development of new interesting inorganic-organic hybrid layered and porous luminescence materials using nitrogen ligands is in progress in our laboratory.

\section{Conclusions}

In this work, new nine lanthanide compounds containing the non-steroidal anti-inflammatory drug (NSAID) Ibuprofen (Ibf) as ligand were synthesized: three mononuclear $\left[\operatorname{Ln}(\operatorname{Ibf})_{3}\left(\mathrm{H}_{2} \mathrm{O}\right)_{2}\right.$ ] $(\mathrm{Ln}=\mathrm{Eu} \quad \mathbf{1} ; \mathrm{Gd} 2$; $\mathrm{Tb}$ 3) and six binuclear complexes $\left[\operatorname{Ln}_{2}(\mathrm{Ibf})_{6}(\text { bpy })_{2}\right](\operatorname{Ln}=\mathrm{Eu} \mathrm{4}$; Gd 5 and $\mathrm{Tb}$ 6, bpy=2,2'-bipyridine) and $\left[\operatorname{Ln}_{2}(\mathrm{Ibf})_{6}(\text { phen })_{2}\right](\mathrm{Ln}=\mathrm{Eu} \mathrm{7;}$ Gd 8 and Tb 9, phen=1,10-phenanthroline). All these compounds were fully characterized and their photophysical properties were studied in detail. According to the photoluminescence study, the phosphorescence broad bands from ligands are not present in any spectra, which suggest that the intramolecular ligand-to-metal energy transfer is efficient, mainly in the binuclear compounds. The theoretically predicted values of intramolecular energy transfer rates of the $\mathrm{Eu}^{\mathrm{III}}$ complexes, from RM1 ground-state geometry, indicate that the energy transfer is predominant from the lowest ligand triplet state $\left(\mathrm{T}_{1}\right)$ of the ligands to the ${ }^{5} \mathrm{D}_{1}$ and ${ }^{5} \mathrm{D}_{0}$ levels of the Eu ${ }^{\mathrm{III}}$ ion. Regarding the spectralluminescent properties of Ibuprofen-lanthanide complexes, the most of the works is focused in the development of luminescent methods for the determination of NSAID - as Ibuprofen - not being known nothing about the energy transfer mechanism in this compounds. Thus, to the best of our knowledge, this is the first work that combines experimental and theoretical results of lanthanide complexes containing the Ibuprofen ligand. The results confirms that substitution of coordinated water molecules in [ $\mathrm{Ln}$ $(\mathrm{Ibf})_{3}\left(\mathrm{H}_{2} \mathrm{O}\right)_{2}$ ] by N,N-donors ligands (bpy or phen) leads the formation of the binuclear compounds of general formula $\left[\operatorname{Ln}_{2}(\mathrm{Ibf})_{6}(\text { bpy })_{2}\right]$ and $\left[\operatorname{Ln}_{2}(\mathrm{Ibf})_{6}(\text { phen })_{2}\right]$, increasing considerably the quantum efficiency values for these compounds and producing intense monochromatic emission colors. All these results, suggests that these binuclear compounds can be excellent for the development of efficient luminescent devices and biomarkers.

\section{Acknowledgments}

This work is a collaboration research project of members of the Rede Mineira de Química (RQ - MG) supported by FAPEMIG (Project: REDE-113/10; Project: CEX-RED-00010-14). The authors are also very grateful to Dr. Thiago Frances (Fundação Oswaldo Cruz - FioCruz/RJ) by the donation of the (R,S) - Ibuprofen and Prof. Dr. Sidney José Lima Ribeiro (IQ - UNESP) by the support with the luminescent facilities.

\section{Appendix A. Supplementary material}

Supplementary data associated with this article can be found in the online version at http://dx.doi.org/10.1016/j.jlumin.2016.09.024. 


\section{References}

[1] S.V. Eliseeva, J.-C.G. Bunzli, New J. Chem. 35 (2011) 1165.

[2] D. Ananias, M. Kostova, F.A.A. Paz, A.N.C. Neto, R.T. De Moura Jr., O.L. Malta, L.D. Carlos, J. Rocha, J. Am. Chem. Soc.. 131 (2009) 8620.

[3] J.-C.G. Bunzli, S.V. Eliseeva, Chem. Sci. 4 (2013) 1939.

[4] X. Wang, X.G. Kong, Y. Yu, Y.J. Sun, H. Zhang, J. Phys. Chem. C 111 (2007) 15119.

[5] J. Kido, Y. Okamoto, Chem. Rev. 102 (2002) 2357.

[6] M. Sun, H. Xin, K.Z. Wang, Y.A. Zhang, L.P. Jin, C.H. Huang, Chem. Commun. (2003) 702.

[7] S. Pandya, J.H. Yu, D. Parker, Dalton Trans. (2006) 2757.

[8] S. Faulkner, S.J.A. Pope, B.J. Burton-Pye, Appl. Spec. Rev. 40 (2005) 1.

[9] L.F. Marques, C.C. Correa, H.C. Garcia, T.M. Francisco, S.J.L. Ribeiro, J.D.L. Dutra, R.O. Freire, F.C. Machado, J. Lumin. 148 (2014) 307.

[10] N. Sabbatini, M. Guardigli, J.M. Lehn, Coord. Chem. Rev. 123 (1993) 201.

[11] N.M. Shavaleev, S.V. Eliseeva, R. Scopelliti, J.-C.G. Bunzli, Inorg. Chem. 49 (2010) 3927.

[12] L.F. Marques, A. Cuin, G.S.G. de Carvalho, M.V. dos Santos, S.J.L. Ribeiro, F.C. Machado, Inorg. Chim. Acta 441 (2016) 67.

[13] D.A. Gálico, B.B.C. Holanda, R.B. Guerra, A.O. Legendre, D. Rinaldo, O. TreuFilho, G. Bannach, Termochim. Acta 575 (2014) 226.

[14] I.M.P. e Silva, D.M. Profirio, R.E.F. de Paiva, M. Lancellotti, A.L.B. Formiga, P.P. Corbi, J. Mol. Struct. 1049 (2013) 1.

[15] A.T.M. Fiori, W.R. Lustri, A. Magalhães, P.P. Corbi, Inorg. Chem. Comm. 14 (2011) 738 .

[16] F.A. Cotton, D.O. Silva, Inorg. Chim. Acta 249 (1996) 57.

[17] G. Ribeiro, M. Benadiba, A. Colquhoun, D.O. Silva, Polyhedron 27 (2008) 1131.

[18] N. Selivanova, K. Vasilieva, Y. Galyametdinov, Luminescence 29 (2014) 202.

[19] A.V. Egorova, A.V. Anelchyk, I.I. Leonenko, Yu. V. Skripinets, V.P. Antonovich, J. Anal. Chem 70 (4) (2015) 440.

[20] S. Biju, D.B. Ambili, M.L.P. Reddy, B.M. Kariuki, Inorg. Chem. 45 (2006) 10651.

[21] W.J. Chai, W.X. Lin, X.J. Sun, T. Ren, X.Y. Shi, J. Lumin. 131 (2011) 225.

[22] A.S. Borges, J.D.L. Dutra, R.O. Freire, R.T. Moura, J.G. da Silva, O.L. Malta, M.H. Araújo, H.F. Brito, Inorg. Chem. 51 (2012) 12867.

[23] R.Q. Albuquerque, R.O. Freire, O.L. Malta, J. Phys. Chem. A 109 (2005) 4607.

[24] M.E. Mesquita, F.R.G.E. Silva, R.Q. Albuquerque, R.O. Freire, E.C. da Conceição, J.E.C. da Silva, N.B.C. Júnior, G.F. de Sá, J. Alloy. Compd. 366 (2004) 124.

[25] G.B. Rocha, R.O. Freire, A.M. Simas, J.J.P. Stewart, J. Comput. Chem. 27 (2006) 1101.

[26] H.A. Flaschka, EDTA Titrations, Pergamon Press, Oxford, 1964.

[27] W.T. Carnall, H.M. Crosswhite, Energy Structure and Transitions Probabilities in $\mathrm{LnF}_{3}$ of the Trivalent Lanthanides, Argonne National Laboratory Report, Argonne, IL, 1977.

[28] R. Pavithran, N.S.S. Kumar, S. Biju, M.L.P. Reddy, S.A. Júnior, R.O. Freire, Inorg. Chem. 45 (2006) 2184

[29] M. Dolg, H. Stoll, H. Preuss, J. Chem. Phys. 90 (1989) 1730.

[30] R.O. Freire, G.B. Rocha, A.M. Simas, J. Mol. Model 12 (2006) 373.

[31] D.A. Rodrigues, N.B. da Costa, R.O. Freire, J. Chem. Inf. Model 51 (2011) 45.

[32] R.O. Freire, G.B. Rocha, A.M. Simas, Inorg. Chem. 44 (2005) 3299.

[33] R.O. Freire, G.B. Rocha, A.M. Simas, J. Braz. Chem. Soc. 20 (2009) 1638.

[34] R.O. Freire, A.M. Simas, J. Chem. Theory Comput. 6 (2010) 2019.

[35] J.D.L. Dutra, M.A.M. Filho, G.B. Rocha, R.O. Freire, A.M. Simas, J.J.P. Stewart, J. Chem. Theory Comput. 9 (2013) 3333.
[36] M.A.M. Filho, J.D.L. Dutra, G.B. Rocha, R.O. Freire, A.M. Simas, Rsc. Adv., 3 , (2013) 16747.

[37] M.A. Filho, J.D.L. Dutra, H.L. Cavalcanti, G.B. Rocha, A.M. Simas, R.O. Freire, J. Chem. Theory Comput. 10 (2014) 3031

[38] J.E. Ridley, M.C. Zerner, Theor. Chim. Acta 42 (1976) 223.

[39] M.C. Zerner, G.H. Loew, R.F. Kirchner, U.T. Muellerwesterhoff, J. Am. Chem. Soc 102 (1980) 589

[40] F. Neese, Wires Comput. Mol. Sci. 2 (2012) 73

[41] A.J. Freeman, J.P. Desclaux, J. Magn. Magn. Mater. 12 (1) (1979) 11.

[42] O.L. Malta, S.J.L. Ribeiro, M. Faucher, P. Porcher, J. Phys. Chem. Solids 52 (4) (1991) 587.

[43] J.D.L. Dutra, N.B.D. Lima, R.O. Freire, A.M. Simas, Sci. Rep. 5 (2015) 13695.

[44] O.L. Malta, F.R.G.E. Silva, Spectrochim. Acta A 54 (1998) 1593.

[45] T. Kushida, J. Phys. Soc. Jpn. 34 (5) (1973) 1318.

[46] A.A. Coelho, J. Appl. Cryst. 36 (2003) 86.

47] TOPAS-R, Version 4.2, General Profile and Structure Analysis Software for Powder Diffraction Data, Bruker AXS, Karlsruhe, Germany, 2009.

[48] G.S. Pawley, J. Appl. Cryst. 14 (1981) 357.

[49] A.L. Spek, Acta Cryst. D65 (2009) 148.

[50] A. Coelho, J. Appl. Cryst. 22 (2000) 899.

[51] N. Shankland, A.J. Florence, P.J. Cox, D.B. Sheen, S.W. Love, N.S. Stewart, C.C. Wilson, Chem. Commun. (1996) 855.

[52] J.H.B. Nunes, R.E.F. de Paiva, A. Cuin, A.M.F. da Costa, W.R. Lustri, P.P. Corbi, J. Mol. Struct. 112 (2016) 14.

[53] S.A. da Silva, C.Q.F. Leite, F.R. Pavan, N. Masciocchi, A. Cuin, Polyhedron 79 (2014) 170.

[54] T.C. Amaral, G.S.G de Carvalho, A.D. da Silva, P.P. Corbi, N. Masciocchi, E.E. Castellano, A. Cuin, J. Coord. Chem. 67 (2014) 1380.

[55] G.B. Deacon, R.J. Phillips, Coord. Chem. Rev. 33 (1980) 227.

[56] P.P. Lima, M.M. Nolasco, F.A.A. Paz, R.A.S. Ferreira, R.L. Longo, O.L. Malta, L.D. Carlos, Chem. Mater. 25 (2013) 586.

[57] O.V. Dolomanov, L.J. Bourhis, R.J. Gildea, J.A.K. Howard, H. Puschmann, J. Appl Cryst. 42 (2009) 339.

[58] D.A. Gálico, M.G. Lahoud, M.R. Davolos, R.C.G. Frem, T.F.C. Fraga-Silva, J. Venturini, M.S.P. Arruda, G. Bannach, J. Inorg. Biochem. 140 (2014) 160.

[59] M.G. Lahoud, R.C.G. Frem, D.A. Gálico, G. Bannach, M.M. Nolasco, R.A. S. Ferreira, L.D. Carlos, J. Lumin. 170 (2015) 357.

60] D.B. Ambili Raj, S. Biju, M.L.P. Reddy, Inorg. Chem. 47 (2008) 8091.

[61] O.L. Malta, H.F. Brito, J.F.S. Menezes, F.R. Gonçalves e Silva, S. Alves Jr., F.S. Farias Jr., A.V.M. de Andrade, J. Lumin. 75 (1997) 255.

62] S. Tobita, M. Arakawa, I. Tanaka, J. Phys. Chem. 89 (1985) 5649.

[63] S. Tobita, M. Arakawa, I. Tanaka, J. Phys. Chem. 88 (1984) 2697.

[64] F.J. Steemers, W. Verboom, D.N. Reinhoudt, E.B. Vander Tol, J.W. Verhoeven, J. Am. Chem. Soc. 117 (1995) 9408.

65] S.T. Frey, H.D. Horrocks, Inorg. Chim. Acta 229 (1995) 383.

[66] L.D. Carlos, O.L. Malta, R.Q. Albuquerque, Chem. Phys. Lett. 415 (2005) 238.

67] W.M. Faustino, O.L. Malta, E.E.S. Teotônio, H.F. Brito, A.M. Simas, G.F. de Sá, J. Phys, Chem. A 110 (2006) 2510.

[68] C.Y. Su, M.Y. Tan, N. Tang, W. Liu, X. Wang, J. Coord. Chem. 38 (1996) 207.

[69] M. Latva, H. Takalo, V.M. Mukkala, C. Matachescu, J.C. Rodriguez-Ubis J. Kanakare, J. Lumin. 75 (1997) 149.

[70] Y.S. Yang, M.L. Gong, Y.Y. Li, H.Y. Lei, S.L. Wu, J. Alloy. Compd. 112 (1994) 207. 